\title{
Reading at exposed surfaces: theoretical insights into photocatalytic activity of $\mathrm{ZnWO}_{4}$
}

\author{
Amanda F. Gouveia ${ }^{1}$, Marcelo Assis ${ }^{2}$, Laécio S. Cavalcante ${ }^{1}$, Lourdes Gracia ${ }^{3,4}$, Elson \\ Longo $^{2}$, Juan Andrés \\ ${ }^{1}$ PPGQ-CCN-DQ, Universidade Estadual do Piauí, P.O. Box 381, 64002-150 Teresina, PI, Brazil \\ ${ }^{2}$ CDMF, Universidade Federal de São Carlos, P.O. Box 676, 13565-905 São Carlos, SP, Brazil \\ ${ }^{3}$ Department of Analytical and Physical Chemistry, University Jaume I, 12071 Castelló, Spain \\ ${ }^{4}$ Department of Physical Chemistry, University of Valencia (UV), 46100, Burjassot, Spain \\ *Corresponding Author. Email: amandafernandes.gouveia@gmail.com \\ Received: 14 December 2018, Accepted: 26 December 2018, Published Online: 28 December 2018 \\ Citation Information: Amanda F. Gouveia, Marcelo Assis, Laécio S. Cavalcantel Lourdes Gracia, Elson Longo, Juan Andrés. Frontier Research Today 2018;1:1005. doi: 10.31716/ \\ frt.201801005 Cite in Other Styles
}

ABSTRACT: Understanding the criteria warranting the existence, stability, and activity of a given configuration of atoms has pivotal relevance in chemical and materials science. Photocatalysts, traditionally semiconductors, are essential for processes ranging from water purification to water splitting, air filtration, and surgical instrument sterilization, and harvest optical energy to drive chemical reactions. These semiconductors harvest optical energy to drive chemical reactions. With chemical reactions

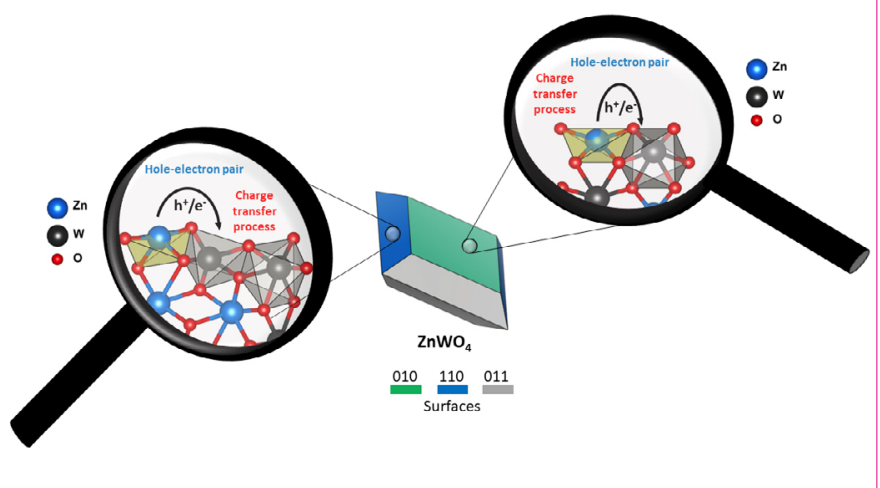
dictated by atomic and molecular interactions at the nanoscale, examining these processes with near-atomic resolution is necessary to understand photochemical processes in depth and to improve materials for next-generation catalysts. The performance and key electronic properties of semiconductors are dictated by the interplay between the surface chemistry and morphology, whose manipulation has inspired experimental and theoretical researchers. This interplay has been clarified by theoretical studies based on atomic-scale modelling with particular attention given to two sets of degreesof-freedom: the atomic positions and chemical configuration. This perspective article presents the major computational challenges and modern methodological strategies toward advancing the field. The $\mathrm{ZnWO}_{4}$ material was selected as a case study, and the key concepts developed in recent years are discussed to clarify the morphology, i.e., the exposed surfaces of materials, and explain its functional properties or performance. First-principle calculations capture the geometric and electronic effects on the photocatalytic activity in agreement with experimental data. Indeed, important and often surprising structure-function relations have been observed based in depth atomistic modelling on morphological analysis. An overview of past achievements and future directions is provided according to the authors' outlook.

Keywords: $\mathrm{ZnWO}_{4}$; First-principle calculation; Geometric effect; Electronic effect; Photocatalytic activity; Atomistic modelling

\section{MORPHOLOGY THAT MATTERS}

Although controlling the geometric shape taken by an inorganic material may be initially considered as scientific curiosity, its implications go far beyond aesthetic appeal. Morphologies are important in chemistry and materials science. The morphology control of materials from the nanoscopic to the macroscopic scales can contribute to the improvement and induce the emergence of properties ${ }^{1,2}$. A recurring theme with regard to the surface chemistry of many materials is the control over the morphology of crystals, which is a very active area of research because most of the physical and chemical properties are shape-dependent. The morphology does not only control the material's physicochemical properties, but also determines its relevance and merit with regard to technological applications ${ }^{3-6}$.
Anisotropy is a basic property of single crystals, by which they exhibit different physical and chemical properties on various surfaces and in diverse directions. The surface properties of materials are highly depended on the material's morphology, which is composed of different exposed crystal surfaces. These exposed surfaces display a different surface atomic arrangement and local coordination. At the atomic level, the surface atoms have lower coordination number than those in the bulk; consequently, those surface atoms with changed atomic structure and free energy exhibit high chemical reactivity. Such characteristics entail surface chemistry treatment a favored approach for various applications $^{7-9}$. The micro-and nano-crystal morphology significantly influences the end-use efficacy of these solid products, which improves the properties of functional materials, such as the reactivity of catalysts, i.e., the performance of catalytic processes depends on how the desired 
reactions are favored at the exposed catalyst surfaces. This is decided by the number and nature of the active sites and the catalytic efficiency ${ }^{10-15}$, the bactericide and sensor activities, and so on. To maximize the exposed surface for a given load catalyst at the nanoscale, metal nanoparticles have been widely employed in a wide range of catalytic systems ${ }^{16-18}$. In particular, the growth process of polyhedral crystals has been explored with significant interest not only due to the emergence of new or enhanced properties from selected crystal surfaces, but also due to the opportunity for fundamental studies on the control nucleation and growth kinetics involved along the crystallization mechanism ${ }^{19}$.

In recent years, several studies have attempted to establish correlation between the morphology, properties, and applications for both micro- and nano-materials ${ }^{20-27}$. For example, in the field of catalysis, the presence of high-index facets at the crystal morphology is more desirable, in comparison with their low-index faced counterparts, because they have low coordinated surface atoms that are exposed on such facets, which can serve as highly catalytic active sites $^{28-30}$. A high-index facet has a higher density of under-coordinated atoms, steps, edges, and kinks that serve as preferred, highly active catalytic sites ${ }^{31-34}$. Depending on the arrangement and distribution of surface facets, nanocrystals with a high-index surface can be prepared with different morphologies. In the case of noble-metal nanocrystals, it is well known that the exposed surfaces are terminated in low-index facets such as (110), (111), and (100) surfaces, owing to their low specific surface free energies relative to other surface types ${ }^{35}$. For example, the most reported morphologies of $\mathrm{Pt}$ nanocrystals are octahedrons composed of (111) surfaces ${ }^{36-38}$, cubes dominated by (100) surfaces $^{38-43}$, and cuboctahedrons wherein both the (111) and (100) exposed surfaces appear ${ }^{44,45}$. However, when high-index surfaces in the morphology of noble-metal nanocrystals are obtained, a substantial enhancement of catalytic activities is observed ${ }^{33,46}$.

Druce et al. ${ }^{47}$ have presented an experimental study, wherein they demonstrated that perovskite oxide $\mathrm{ABO}_{3}$ surfaces always exhibit AO-surface termination when exposed to elevated temperatures under high oxygen pressure. Consequently, the catalytically active transition metals on the B-site are buried in the subsurface layer, while the A-site cations are exposed at the solid/gas interface. Additionally, Staykov et al. ${ }^{48}$ concluded that the catalytic activity of the AO-terminated perovskite surfaces strongly depends on the presence of surface oxygen vacancies, which expose the electronic states of the $\mathrm{BO}_{2}$-sublattice to the gas/solid interface. In particular, the electronic properties in the vicinity of the surface oxygen vacancies of $\mathrm{SrTiO}_{3}$ have shown that such vacancies are not simply spatial voids, but rather regions in space that are characterized by high electron density $^{49}$. Because of the molecular oxygen activation and dissociation in an electrophilic reaction, surface oxygen vacancies are the preferred surface active sites. Additionally, the oxygen vacancies on the $\mathrm{SrO}$ surface of $\mathrm{SrTiO}_{3}$ exhibit the tendency of pairing, owing to the electronic relaxation in the vicinity of the vacancy pair ${ }^{48}$. In this context, Feng et al. ${ }^{50}$ have summarized the recent progress of research on the crystal facet tailoring arts in perovskite structure oxides. SEMICONDUCTOR MATERIALS
Photocatalysis is an appealing approach toward tackling environmental and global energy problems. Over the past decade, semiconductor photocatalysts with tailored morphologies have attracted intense research interest in many research fields, such as the photocatalytic degradation of pollutants $^{51}$, water splitting ${ }^{52-54}$, and photocatalytic antibacterial fields ${ }^{55,56}$, owing to their many intrinsic shape-dependent properties ${ }^{57,58}$. Additionally, the exposed surfaces appearing on the morphology do not only determine the intrinsic physical and chemical properties, but also provide new technological applications in catalysis, optics, electronics, and magnetics. Extensive investigations have been carried out with regard to the dependency of the surface on photocatalytic activity ${ }^{59-61}$. Generally, exposed surfaces play a key role in the photocatalytic efficiency by involving three main factors: (i) by tuning band electronic structures ${ }^{62,63}$; (ii) by providing high active facets/sites ${ }^{64}$; (iii) by increasing the selective oxidation or reduction activity ${ }^{65}$.

In this context, Mclaren et al. ${ }^{66}$ reported that the photocatalytic activity of $\mathrm{ZnO}$ depends on the fraction of the exposed (001) surface's crystal face. $\mathrm{Xi}$ and $\mathrm{Ye}^{67}$ reported that $\mathrm{BiVO}_{4}$ with (100) exposed surface facets displays an enhanced photocatalytic activity for Rhodamine B (RhB) degradation and $\mathrm{O}_{2}$ evolution. Moreover, $\mathrm{Li}$ et al. ${ }^{22}$ have demonstrated that the (110) surface of $\mathrm{BiVO}_{4}$ enhanced the photocatalytic activity. In $\mathrm{Ag}_{3} \mathrm{PO}_{4}$, rhombic dodecahedra morphology with (110) exposed surfaces exhibits much higher activities than cubes with (100) exposed surfaces for the photocatalytic degradation of organic contaminants ${ }^{20}$. Zhang et al. ${ }^{68}$ have investigated the photocatalytic oxidization activity order of $\mathrm{NaNbO}_{3}$ with low-indexed surfaces. Many exposed surfaces in different semiconductor photocatalysts have been shown to be efficient in increasing photocatalytic activities, such as (001) in $\mathrm{TiO}_{2}{ }^{69}$ and (100) in $\mathrm{WO}_{3}{ }^{70}$. Very recently, $\mathrm{Lu}$ et al. ${ }^{71}$ reported that the $\mathrm{BaZrO}_{3}$ nanocrystals with the (001)/(011) facets and a corresponding higher reduction capacity could effectively improve the photocatalytic hydrogen evolution in pure water.

An advanced understanding of the chemical and physical factors determining the properties and performance of semiconductors is an obvious prerequisite toward the systematic improvement of their mobility and stability. In our laboratories, it has been a long-standing objective to develop platforms that enable the experimental and computational investigation of semiconductors through modeling. In this research field, our group has developed different semiconductors such as $\alpha-\mathrm{Ag}_{2} \mathrm{WO}_{4}, \mathrm{Ag}_{3} \mathrm{PO}_{4}: \mathrm{Mo}, \mathrm{PbMoO}_{4}$, HA@Ag (hydroxyapatite decorated with silver), $\mathrm{ZnWO}_{4}$, $\mathrm{NiWO}_{4}$, and $\alpha-\mathrm{AgVO}_{3}$ with good performance as photocatalytic materials for the degradation of organic dyes ${ }^{72-76}$ and antibacterial agents ${ }^{77-81}$.

In simple terms, a photocatalytic reaction on a semiconductor includes at least five main steps ${ }^{82}$ : i) light absorption by the semiconductor, ii) formation of photogenerated electron $\left(\mathrm{e}^{-}\right)$and hole $\left(\mathrm{h}^{+}\right)$pairs. The optical absorption induces the transfer of electrons from the valence band (VB) to conduction band (CB), generating the electron/ hole $\left(\mathrm{e}^{-} / \mathrm{h}^{+}\right)$pairs ${ }^{83}$. iii) migration and recombination of the photogenerated electron-hole pairs. After these transfer processes, $\mathrm{e}^{-}$and $\mathrm{h}^{+}$are capable to migrate from the bulk to the surface to participate in oxidation and reduction reactions, respectively. Meanwhile, electrons and holes can also 
recombine and dissipate heat in the pathway of transport to surface, which produces negative effect on photocatalysis. iv) adsorption of reactants and desorption of products, and $v$ ) occurrence of redox reactions on the semiconductor surface. A schematic representation of the different steps along the photocatalytic process on a typical semiconductor is presented in Figure 1.

The behavior of the $\mathrm{e}^{-}$and $\mathrm{h}^{+}$charge carriers at the semiconductor surfaces controls the performance of important applications, including photocatalysts and solar cells ${ }^{84}$, because the photocatalytic reaction occurs only when photo-excited $\mathrm{e}^{-}$and $\mathrm{h}^{+}$are available on the surface $\mathrm{e}^{85,86}$ and need to be efficiently separated and transferred away from each other to enhance the performance. The nature and mechanisms by which $\mathrm{e}^{-}$and $\mathrm{h}^{+}$form, and their role in photocatalysis, remain uncertain. Moreover, $\mathrm{e}^{-}$can transport through the material potentially trapped at the lattice sites in the bulk or at the surface. Thus, they can affect the conductivity and interaction with the surface-adsorbed species. Then, $\mathrm{e}^{-}$can potentially promote conductivity in the material or affect the surface reaction mechanisms. However, they can also form carrier recombination centers, which are detrimental to photoconductivity. These charge carriers in oxide semiconductors can be delocalized or can be selftrapped to form small polarons ${ }^{87}$.

When a photocatalyst absorbs light, it generates electron/ hole $\left(\mathrm{e}^{-} / \mathrm{h}^{+}\right)$pairs such that electrons and holes can react with water $\left(\mathrm{H}_{2} \mathrm{O}\right)$ and dissolved oxygen $\left(\mathrm{O}_{2}\right)$ separately to generate reactive oxygen species (ROS) ${ }^{88,89}$. These ROS, such as the hydroxyl radical $(\mathrm{OH} \bullet)$, superoxide radical $\left(\mathrm{O}_{2}\right.$ $\left.{ }^{\cdot}\right)$, and singlet oxygen $\left({ }^{1} \mathrm{O}_{2}\right)$, are capable of disinfecting pathogens by damaging the essential macromolecules and active agents to react with the exposed surfaces of the semiconductor. Additionally, they are responsible for the corresponding photocatalytic activity. Photocatalytic activities are also closely related to their electronic structures, and the value of the band gap determines the light absorption range of the semiconductor and the number of photo-generated $\mathrm{e}^{-} / \mathrm{h}^{+}$pairs. Additionally, the positions of the $\mathrm{CB}$ bottom and VB top are key considerations in explaining

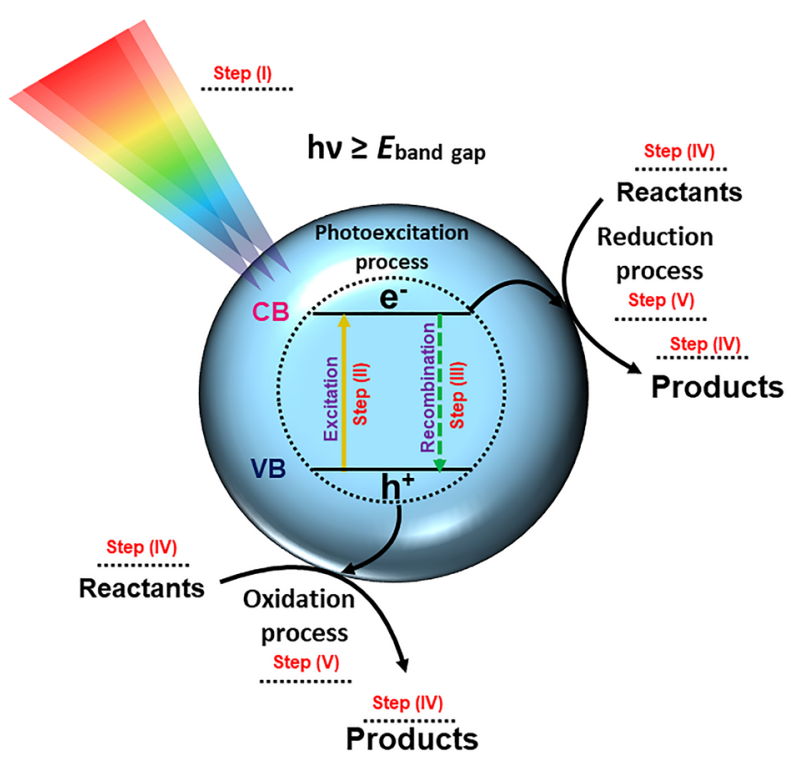

Figure 1. Schematic representation of photocatalytic process. the reduction and oxidation abilities of photogenerated electrons and holes, respectively. From a thermodynamic viewpoint, the reduction potential of the electron acceptors should be energetically below the CB bottom of a semiconductor, while the oxidization potential level of the electron donors should be above the VB top. A deep position of the VB implies a high cost of extracting electrons from the $2 p$ levels of the $\mathrm{O}_{2}{ }^{-}$anions. A high $\mathrm{CB}$ position implies a moderate tendency toward accepting electronic charge, which results in low reactivity and chemical inertness. Moreover, the value of the band gap size is also important because it determines the light absorption range of the semiconductor and the number of photo-generated electron/hole pairs. For example, Yu et al. ${ }^{90}$ prepared $\mathrm{FeWO}_{4}$ samples with different morphologies by varying the $\mathrm{pH}$ values during the hydrothermal process, and systematically investigated their optical properties. Their results revealed that the band-gap values of $\mathrm{FeWO}_{4}$ correlated with specific morphologies. From a thermodynamic viewpoint, the reduction potential of the electron acceptors should be energetically below the $\mathrm{CB}$ bottom of a semiconductor, while the oxidization potential level of the electron donors should be above the VB top.

Amongst all factors influencing the photocatalytic activity, the morphology and exposed surfaces play a major role by providing a higher surface area, which leads to the higher adsorption of dye molecules on the surface of the photocatalyst, and to the enhancement of the photocatalytic activity. Then, the surface controlled synthesis of materials, i.e., crystal facet engineering, is not only a promising method of promoting the $\mathrm{e}^{-} / \mathrm{h}^{+}$separation and then inducing the formation of active $\operatorname{ROS}\left(\mathrm{OH} \bullet\right.$ and $\mathrm{O}_{2}{ }^{-}$radicals and singlet oxygen ${ }^{1} \mathrm{O}_{2}$ ) to improve the photocatalytic activity of semiconductor-based photocatalysts $^{91-101}$, but also a rational procedure for investigating the relationships between the surface structures and the photocatalytic properties to develop highly active photocatalysts. Then, crystal-facet engineering plays a central role in the kinetic and thermodynamic modulation of redox reactions at the catalyst's surface ${ }^{102-106}$. Generally, the highly active facets correspond to high-index facets end owed with a more reactive atomic arrangement, termination, and local coordination ${ }^{107-110}$. For example, the results obtained by theoretical and experimental studies reveal that the (001) surface of anatase $\mathrm{TiO}_{2}$ is much more reactive than amore thermodynamically stable (101) surface, and that the (001) surface may in fact be the dominant source of active sites for various applications ${ }^{111-114}$. The surface energies of the (010), (001), and (101) surfaces have been theoretically calculated and reported as $0.53 \mathrm{Jm}^{-2}$, $0.90 \mathrm{Jm}^{-2}$, and $0.44 \mathrm{Jm}^{-2}$, respectively. As can be seen, the surface energy of (010) is slightly higher than that of (101) and much lower than that of $(001)^{115}$. Therefore, it has been reported that faceted- $\mathrm{TiO}_{2}$ with a high percentage of (010) facets exhibits a similar photocatalytic activity with the (001) facet ${ }^{116,117}$. Very recently, Carey and McKenna ${ }^{118}$ provided crucial insights into the behavior of $\mathrm{e}^{-}$and $\mathrm{h}^{+}$in $\mathrm{TiO}_{2}$. These applications are relevant for applications in photocatalysis, and have challenged the common perception where by electrons are trapped at the low index surfaces of anatase $\mathrm{TiO}_{2}$.

Heterogeneous catalysis is another interesting example, where in the many reactions occurring on the surface 
catalysts are highly sensitive, in terms of activity and/or selectivity, to the arrangement (or the coordination number, more precisely) of atoms. Thus, the surface type on the surface is determined by the geometric shape of the micro- nanocrystals ${ }^{119,120}$. For example, Pt cuboctahedrons with (111) and (100) exposed surfaces and a size of $13 \mathrm{~nm}$ are capable of catalyzing the transformation of benzene to both cyclohexane and cyclohexene, while only the cyclohexane product is obtained when the morphology of $\mathrm{Pt}$ is a cube covered by the (100) surface ${ }^{121}$. Similar correlations between the catalytic activity/selectivity and morphology, i.e., the type of the nanocrystal's exposed surface, have also been observed in many other systems ${ }^{122-124}$. These and many other examples clearly illustrate the critical importance of the morphology control to the effective use of materials in a wide variety of applications.

\section{CONCEPT OF SURFACE ENERGY}

The seminal studies of Gibbs and Curie in the late $19^{\text {th }}$ century $^{125}$, and later the application of the well-known Wulff rule, obtained the thermodynamic equilibrium shape and morphology of bare polyhedral crystals with size-independent surface energies ${ }^{126,127}$. Over the last two decades, first-principle calculations based on the Wulff construction have been employed to provide atomistic models of the equilibrium morphologies for micro- and nano-materials in vacuum, liquid, and gas environments ${ }^{128-135}$. The morphology of micro-and nano-materials describes the set of crystallographic planes that appears at the exposed crystal surfaces.

The surface energy is perhaps the most fundamental characteristic of any material and helps in determining the trends of growth rate, surface segregation, and catalytic activity. Generally, crystals grow with the most stable surfaces, and are composed of surfaces with the lowest surface energy, which is high if the crystal facet consists of many kink atoms within the high index planes. Therefore, it is very difficult to grow high index facets in crystals. However, the experimental determination of surface energy is still rather difficult. For nanoparticles in particular, the strong size effect of the surface energy emerges when the particle diameter is less than a few nanometers. However, owing to the small size of nanoparticles, it is very difficult to measure the surface energy experimentally ${ }^{136}$. Therefore, theoretical models and computer simulations must be developed to investigate the surface energy at the nanoscale. Because of the Wulff construction, the equilibrium morphology of a given material can be obtained using ab initio calculations $^{131-134,137-142}$. The procedure to obtain the complete set of morphologies, based on the Wulff construction and the surface energy, has been previously presented and employed as guide to match with experimental morphologies obtained for different binary oxides such as: $\mathrm{Co}_{3} \mathrm{O}_{4}$, $\alpha-\mathrm{Fe}_{2} \mathrm{O}_{3}$, and $\mathrm{In}_{2} \mathrm{O}_{3}{ }^{132}$, as well as metals and metal oxides such as: $\mathrm{Ag}$, anatase $\mathrm{TiO}_{2}$, and $\alpha-\mathrm{Ag}_{2} \mathrm{WO}_{4}{ }^{131}$, and $t-\mathrm{LaVO}_{4}{ }^{133}$, $\mathrm{BaWO}_{4}{ }^{137}, \mathrm{ZnWO}_{4}{ }^{75}, \mathrm{BaMoO}_{4}{ }^{143}, \mathrm{CaMoO}_{4}{ }^{144}$ and $\alpha-\mathrm{AgVO}_{3}{ }^{80}$. Then, we can apply our methodology to develop a consistent and reliable set of models for the morphology and corresponding exposed material surfaces.

Origami is the Japanese word for paper folding and refers to an ancient folding technique that transforms a flat sheet into a complex three-dimensional (3D) shape. There exists a variation of origami called kirigami, which involves both cutting and folding. Origami and kirigami based design principles have recently attracted a growing amount of interest from the scientific and engineering communities, and have enabled a wide variety of promising applications such as self-assembling robots, reconfigurable mechanical metamaterials, self-deployable heart stents, dynamic solar tracking, flexible lithium-ion batteries, and soft actuators $^{145-152}$. Even, at biological level, the invention of DNA origami has deepened the understanding of how molecules could interact with each other in a complex self-assembly process and has accelerated the engineering of molecular systems with custom-designed structures and programmable behaviors ${ }^{153-159}$. In solid state, the concept of crystal origami has been introduced toward the rational design of surface structures of micro- and nano-crystallites ${ }^{144,160,161}$.

The crucial step in semiconductor modeling involves the selection of an approach to ward approximating and describing the system's structural arrangement. Recently, our research group ${ }^{131}$ proposed an adequate methodology based on the Wulff construction for obtaining the available morphologies of a given crystal. This tool is useful in gaining a further understanding of how to achieve the morphological control of $3 \mathrm{D}$ nanocrystals by tuning the ratio of the surface energy values of the different facets. Additionally, we can predict the reaction pathway along the synthetic route and the experimental conditions that are crucial in obtaining the final material morphology and the corresponding properties. Therefore, the modifications of the synthetic route toward forming the determinate morphology are based on the same idea of manipulating a flat sheet in an origamiand kirigami-based design.

\section{CORRELATING MORPHOLOGY AND PHO- TOCATALYTIC ACTIVITY}

Yan et al. ${ }^{162}$ have demonstrated the importance of determining the correlation between the morphology and the determined property in the fabrication and design of nanostructure inorganic semiconductor photocatalysts. $\mathrm{Ng}$ and $\operatorname{Fan}^{160}$ have obtained different morphologies for the $\beta$-Ag${ }_{2} \mathrm{MoO}_{4}$ crystal under different experimental conditions, and analyzed the photocatalytic activity of these morphologies using the degradation of Rhodamine $\mathrm{B}(\mathrm{RhB})$ under visible light irradiation. The authors demonstrated that the surface of the morphology plays an important role in the photocatalytic activity. Moreover, low-index facets exhibit low degradation rates, whereas high-index facets exhibit much higher degradation rates. In a previous study, our research group ${ }^{163}$ obtained a different morphology for $\alpha-\mathrm{Ag}_{2} \mathrm{WO}_{4}$ synthetized with the chemical substitution of $\mathrm{Ag}$ by $\mathrm{Ni}$ atoms using the microwave-assisted hydrothermal method. The presence of $\mathrm{Ni}$ atoms on the $\alpha-\mathrm{Ag}_{2} \mathrm{WO}_{4}$ structure is responsible for the morphology variation, and thus for the variation of the photoluminescence emission profile. Yan and et al. ${ }^{162}$ have synthetized four typical orthorhombic $\mathrm{Bi}_{2} \mathrm{WO}_{6}$ nanostructures using the soluble inorganic-salt-assisted hydrothermal method, and analyzed their photocatalytic tetracycline degradation. In this case, the samples exhibited a morphology-dependent photocatalytic activity, and the deg- 
radation rate values for the $3 \mathrm{D}$ nanostructure were higher than those of the 2D nanostructure. The theoretical calculations can make good predictions for these values, which can in turn provide the information required to clarify the photocatalytic mechanism.

\section{ZINC TUNGSTATE $\left(\mathrm{ZnWO}_{4}\right)$}

Recently, ternary-tungstate-based complex oxides have attracted the attention of researchers as potential candidates for efficient photocatalytic applications, including energy conversion and environmental purification, owing to their striking features such as low cost, environmental efficiency, and high stability under acidic and oxidative conditions $^{164-167}$. As a representative member of this group, zinc tungstate $\left(\mathrm{ZnWO}_{4}\right)$ has received considerable attention, owing to its high thermal stability, excellent optical and electrical properties, and wide range of applications from photocatalytic, photoluminescent, to Li-battery anode materials ${ }^{168-171}$. These $\mathrm{ZnWO}_{4}$ characteristics result from its relatively high valence band and wide band gap ${ }^{172,173}$, which can generate $\mathrm{OH} \bullet$ with a strong oxidizing property to inactivate bacteria ${ }^{174}$

Therefore, $\mathrm{ZnWO}_{4}$ is an ideal photocatalyst for inactivating Macrocystis pyrifera by an integrated $\mathrm{OH} \cdot$ and hot water pretreatment ${ }^{175,176}$. With regard to microorganisms, $\mathrm{ZnWO}_{4}$ has a wide application prospect, owing to its bactericidal effects resulting from the high oxygen evolution potential $^{177,178}$, wherein the generated $\mathrm{OH} \bullet$ has a stronger oxidation ability than $\mathrm{TiO}_{2}{ }^{170,179}$.

Understanding the complicated relationship between various synthetic processing parameters and the functional properties or performance of nanoparticles is one of the objectives in the computational design of materials, and an ideal problem in materials informatics. In clarifying the complex relationship between various synthetic processing parameters, such as temperature, growth rates (moderated by precursors and surfactants), and time, the final functional properties or the performance are the objectives of the computational design of materials, particularly in the engineering of photocatalysts, in addition to being an ideal problem in materials science. The motivation for this study was provided from our previous studies on $\mathrm{ZnWO}_{4}{ }^{75}$. Here, we present our investigation to ward clarifying its photocatalytic activity. Additionally, this study seeks to fulfill a three-fold objective. First, on the basis of the first-principle density function theory (DFT), we investigate the (001), (010), (100), (110), (101), (011), and (111) low-index exposed surfaces of $\mathrm{ZnWO}_{4}$ to clarify their morphology, geometry, and electronic structures. Secondly, in an attempt to illuminate the relationship between the morphology and photocatalytic activity of $\mathrm{ZnWO}_{4}$, we must understand the morphology changes as a function of the relative stability of surfaces. Thirdly, we obtain new clues for understanding the atomic properties and morphology of the $\mathrm{ZnWO}_{4}$ microcrystal and its contribution toward improving the efficiency of the photocatalytic process. Then, the relevant mechanisms are investigated through calculations from first-principles to provide new insight into the high photocatalytic activity of $\mathrm{ZnWO}_{4}$ based on the analysis of the local under-coordination of both $\mathrm{Zn}$ and $\mathrm{W}$ cations in the exposed surfaces covered by the morphology. To this end, the role of the exposed surfaces on the photoactivity of $\mathrm{ZnWO}_{4}$, and particularly the geometry and electronic structure of the incomplete clusters of both $\mathrm{Zn}$ and $\mathrm{W}$ cations, are elucidated using the Kröger-Vink notation and by analyzing the number of the $\mathrm{Zn}-\mathrm{O}$ and $\mathrm{W}-\mathrm{O}$ breaking bonds in these clusters, i.e., the under-coordinated clusters. Thus, we are able to identify that these clusters are the main contributors to the photocatalytic process, which can help us clarify their mechanism.

\section{$\mathrm{ZnWO}_{4}$ BULK AND SURFACE STRUCTURES}

Our group has previously presented the synthesis of $\mathrm{ZnWO}_{4}$ nanocrystals ${ }^{67}$ using the microwave hydrothermal method (HM) at three different temperatures $\left(140{ }^{\circ} \mathrm{C}, 150\right.$ ${ }^{\circ} \mathrm{C}$ and $\left.160^{\circ} \mathrm{C}\right)$. These nanocrystals had a wolframite structure within the monoclinic $P 2 / c^{177,180-183}$ space group. The building blocks of the $\mathrm{ZnWO}_{4}$ structure were the distorted octahedrals of the $\left[\mathrm{ZnO}_{6}\right]$ and $\left[\mathrm{WO}_{6}\right]$ clusters, which generated structural defects in the lattice, as shown in Figure 2.

The results revealed that the different efficiency of the photocatalytic properties was caused by the preferential orientated growth and this orientation is the specific surface in the growth process, as shown in the transmission electronic microscopy (TEM and HR-TEM) images shown

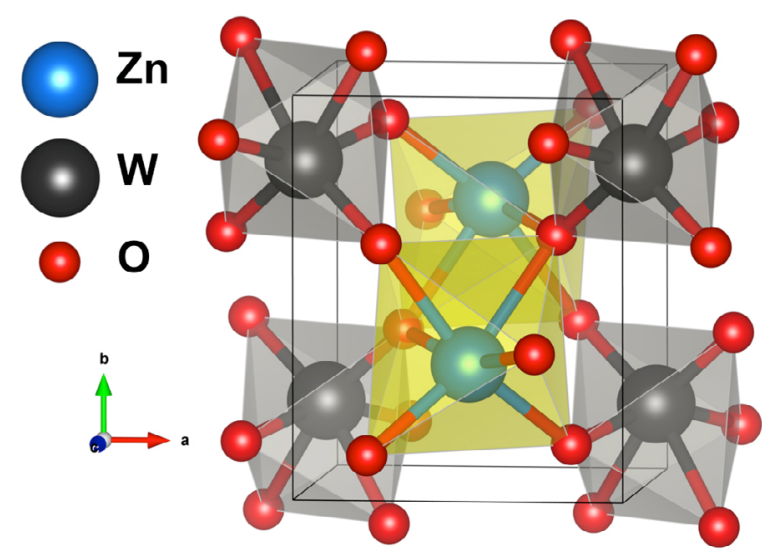

Figure 2. Unit cell representation of monoclinic $\mathrm{ZnWO}_{4}$ structure and octahedral $\left[\mathrm{ZnO}_{6}\right]$ and $\left[\mathrm{WO}_{6}\right]$ clusters. (a)

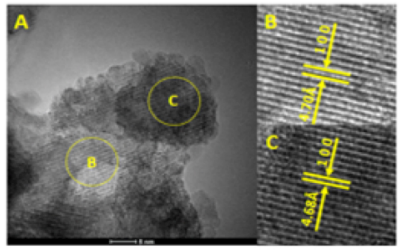

$140{ }^{\circ} \mathrm{C}$

(c)

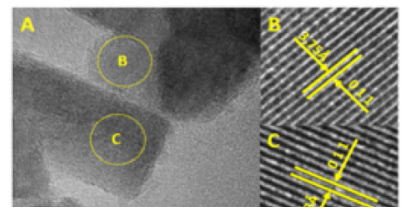

(b)

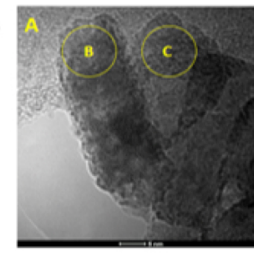

$150^{\circ}$

(d)

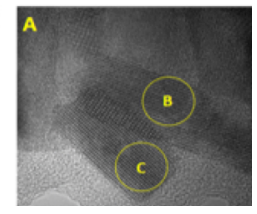

Figure 3. Images of $\mathrm{ZnWO}_{4}$ nanocrystals obtained by Pereira et al. using $\mathrm{MH}$ method at: (a) $140{ }^{\circ} \mathrm{C}$ : A-TEM, B, and C-HR-TEM; (b) $150^{\circ} \mathrm{C}$ : A-TEM, B, and C-HR-TEM; (c) and (d) $160{ }^{\circ} \mathrm{C}$ : A-TEM, B, and C-HR-TEM. Reproduced from Ref. 75 with permission from The Royal Society of Chemistry. 


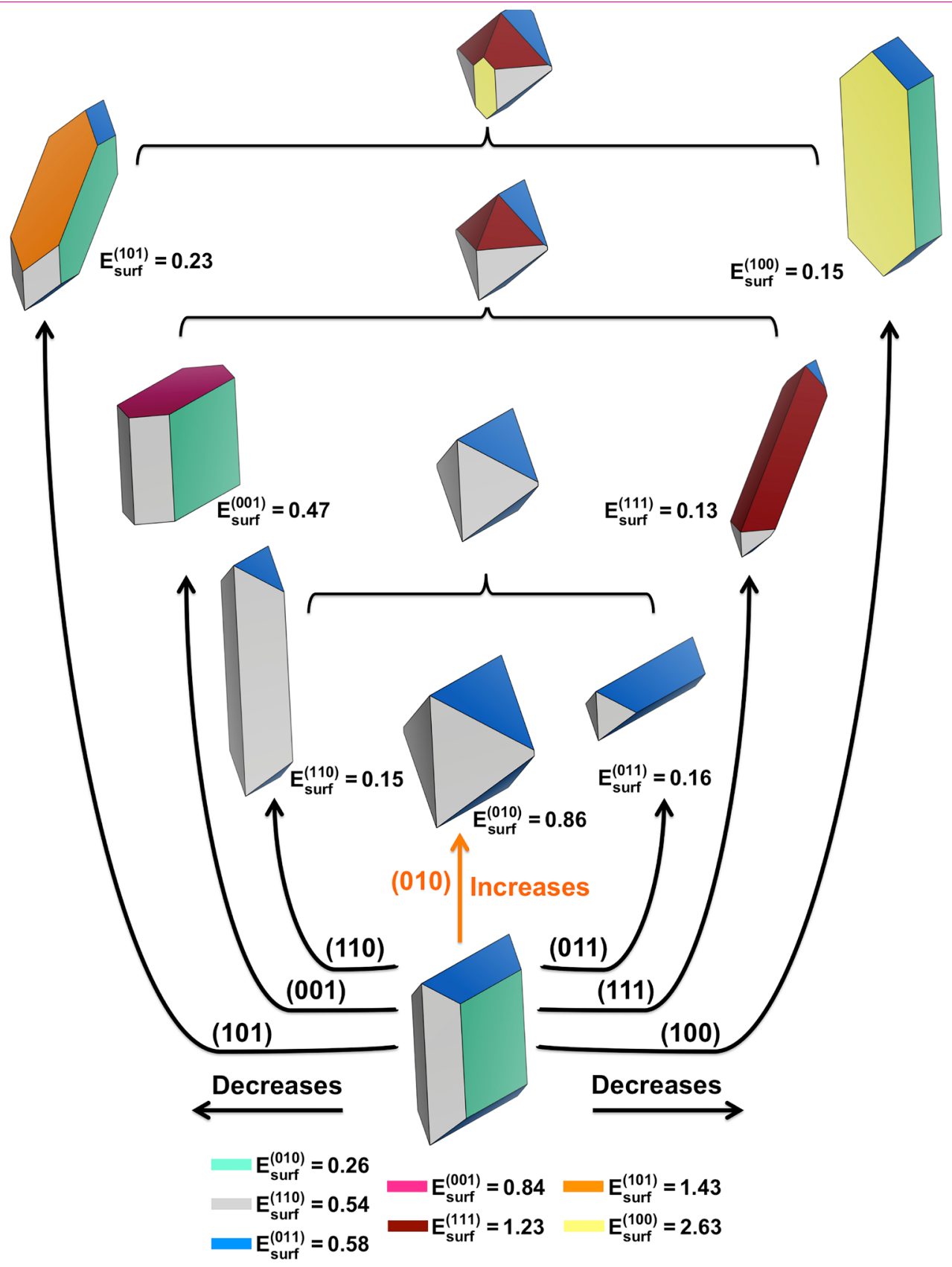

Figure 4. Available morphologies of monoclinic $\mathrm{ZnWO}_{4}$ structure. Surface energy $\left(E_{\text {surf }}\right)$ is in $\mathrm{Jm}^{-2}$.

\section{in Figure 3.}

Understanding the correct surface and surface composition is crucial for their photocatalytic application. To this end, $\mathrm{ZnWO}_{4}$ can be cleaved in various possible crystallographic planes. First, we present the available morphologies of $\mathrm{ZnWO}_{4}$, based on the Wulff construction and the surface energy values calculated for the (001), (010), (100), (110), (101), (011), and (111) surfaces shown in Figure 4.

\section{WHAT MAKES THE DIFFERENCE?}

The most important information from Figure 4 is the presence of the (011) and (010) surfaces in all of the available $\mathrm{ZnWO}_{4}$ morphologies, and the invariant properties involved in their photocatalytic activity ${ }^{75}$.

The TEM and HR-TEM images at different temperatures $\left(140{ }^{\circ} \mathrm{C}, 150{ }^{\circ} \mathrm{C}\right.$, and $160{ }^{\circ} \mathrm{C}$ ) in the synthesis (Figure 3 ) show that the growth mechanism is controlled by the direction of the more stable surfaces in the order of (100) >
$(111)>(011)>(010)$, which can be associated to the experimental MH method used in the synthesis.

The particular crystal orientations lead to differences in the number of broken bonds at each exposed surface, i.e., the anisotropic surface broken bonds ${ }^{184}$, which are known as the anisotropic surface reactivity ${ }^{185,186}$. By carefully analyzing the atomic arrangement of the atoms after the optimization process, it is possible to calculate the broken bond density $\left(D_{\mathrm{b}}\right)$ and observe which clusters are present at the top of each surface. The $D_{\mathrm{b}}$ calculation was proposed by Gao et al. ${ }^{184,187,188}$ and is the ratio between the number of broken bonds $\left(\mathrm{N}_{\mathrm{b}}\right)$ per area $(\mathrm{A})$ for each surface. Table 1 lists the surface energy values ${ }^{75}$ and the broken bond density. Generally, the $D_{\mathrm{b}}$ values are directly linked to the order of the surface energy stability, i.e., higher values of $D_{\mathrm{b}}$ represent a large quantity of defects on the surface and also a higher surface energy value.

Table 1. Values of surface area, broken bond number, 
broken bond density, and surface energy for each $\mathrm{ZnWO}_{4}$ surface.

\begin{tabular}{ccccc}
\hline Surface & $\begin{array}{c}\text { Surface } \\
\text { area }\left(\mathbf{n m}^{2}\right)\end{array}$ & $\begin{array}{c}\text { Broken bond } \\
\text { number }\left(\mathbf{N}_{\mathbf{b}}\right)\end{array}$ & $\begin{array}{c}\text { Broken bond } \\
\text { density } \\
\left(D_{\mathbf{b}}, \mathbf{n m}^{-2}\right)\end{array}$ & $\begin{array}{c}\text { Surface } \\
\text { energy }\left(\mathbf{J m}^{-2}\right)\end{array}$ \\
\hline$(010)$ & 0.236 & 4 & 16.95 & 0.26 \\
$(110)$ & 0.374 & 8 & 21.39 & 0.54 \\
$(011)$ & 0.364 & 6 & 16.48 & 0.58 \\
$(001)$ & 0.277 & 6 & 21.66 & 0.84 \\
$(111)$ & 0.466 & 12 & 25.75 & 1.23 \\
$(101)$ & 0.402 & 8 & 19.90 & 1.43 \\
$(100)$ & 0.290 & 8 & 27.59 & 2.63 \\
\hline
\end{tabular}

The analysis of the results presented in Table 1 shows that the (010) surface has the lower value of surface energy $\left(0.26 \mathrm{Jm}^{-2}\right)$ with the lowest value of the broken bond number $\left(\mathrm{N}_{\mathrm{b}}=4\right)$. The (110) and (011) surfaces have similar surface energy values, i.e., 0.54 and $0.58 \mathrm{Jm}^{-2}$, with different values of $\mathrm{N}_{\mathrm{b}}=8$ and 6 , respectively. Moreover, the (001), (111), (101) and (100) surfaces display the following order of stability: $0.84<1.23<1.43<2.63 \mathrm{Jm}^{-2}$, respectively, with $\mathrm{N}_{\mathrm{b}}=6,12,8$, and 8 , respectively. Therefore, in this case, there does not exist a correlation between the surface stability and the $\mathrm{N}_{\mathrm{b}}$ or broken bond density $D_{\mathrm{b}}$.

Hence, we must find a way to correlate the photocatalytic activity of $\mathrm{ZnWO}_{4}$ with the presence of the different exposed faces in the morphology, independently of the $\mathrm{Nb}$ and $\mathrm{Db}$ values. To this end, we provide the theoretical/computational foundation for the analysis of their electronic properties. Figure 5 illustrates the clusters present in all investigated surfaces for the monoclinic $\mathrm{ZnWO}_{4}$ material. From the analysis of the top of each surface, it is observed that not only the under-coordinated atoms (clusters) are involved in the surfaces, but they are also involved in the distorted clusters. In any case, the crystal shape of interest and this crystal shape depend on the surface structure.

Using the Kröger-Vink notation ${ }^{189}$, the oxygen vacancies

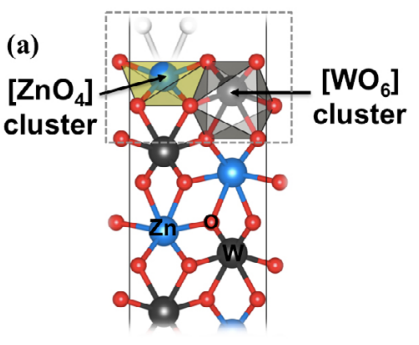

(010) surface
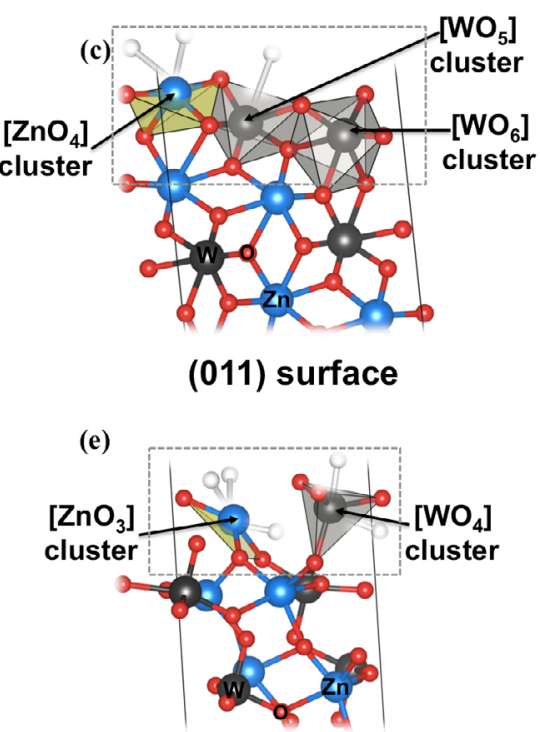

(111) surface

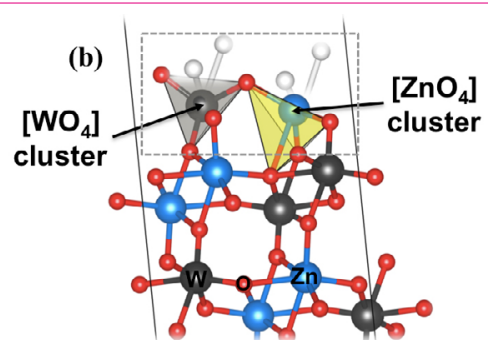

(110) surface
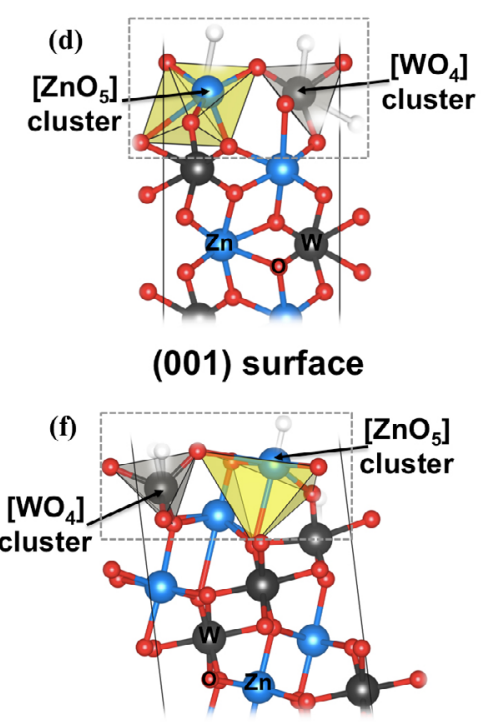

(101) surface

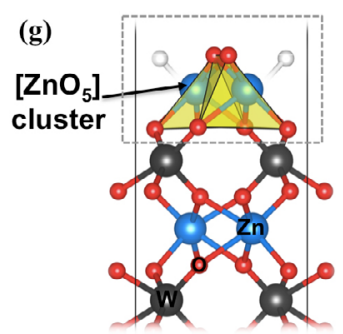

(100) surface

Figure 5. Surface models for monoclinic $\mathrm{ZnWO}_{4}$ structure: (a) (010), (b) (110), (c) (011), (d) (001), (e) (111), (f) (101), and (g) (100) surfaces. The clusters at the top of each surface are highlighted. 


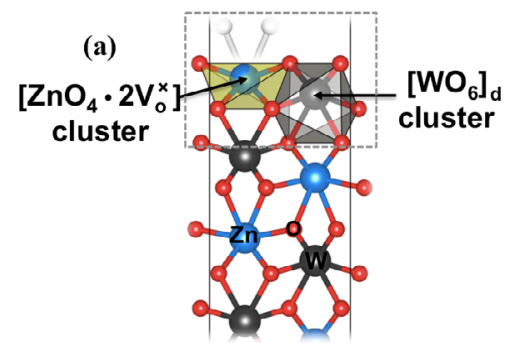

(010) surface

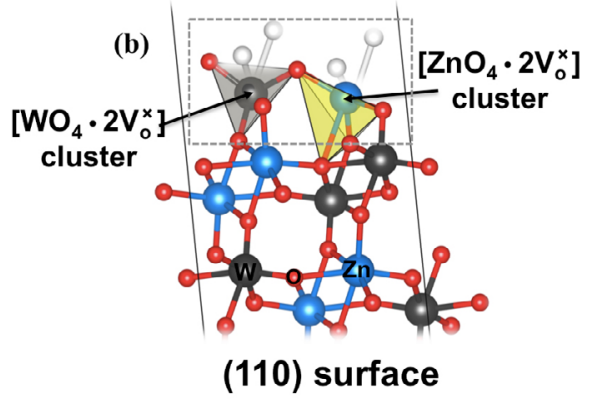

(d)

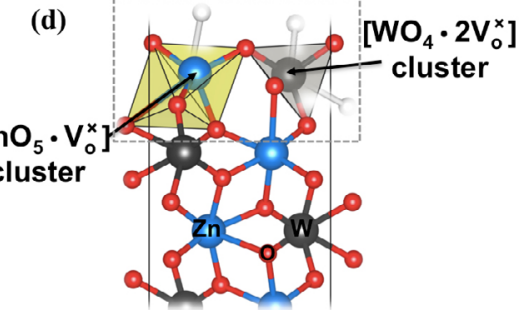

(001) surface

$\mathrm{WO}_{5} \cdot \mathrm{V}_{\mathrm{o}}$

cluster

$\left[\mathrm{WO}_{6}\right]_{\mathrm{d}}$ cluster

(c)

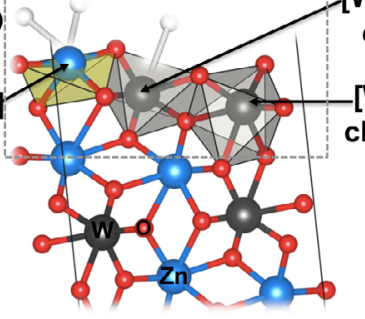

(011) surface

luster

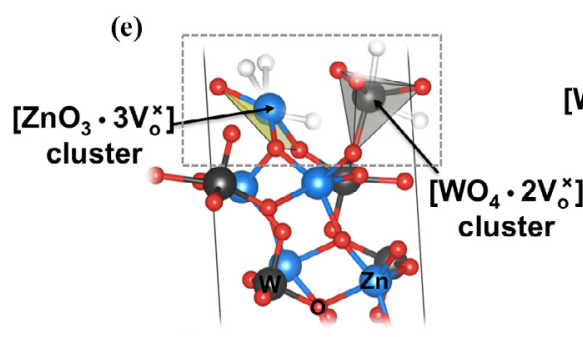

(111) surface

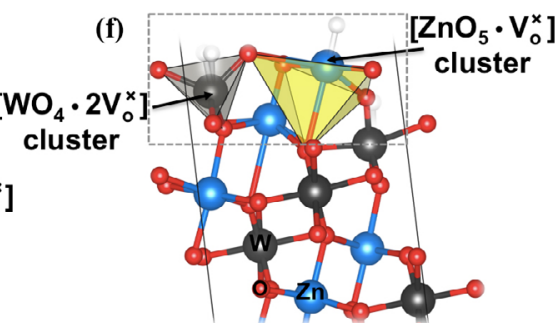

(101) surface

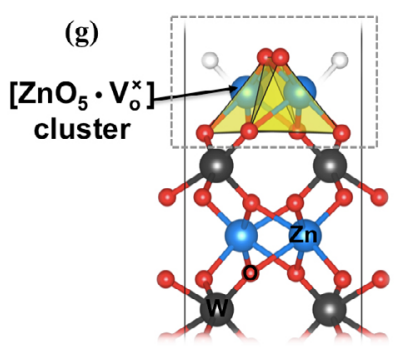

(100) surface

Figure 6. Surface models for monoclinic $\mathrm{ZnWO}_{4}$ structure: (a) (010), (b) (110), (c) (011), (d) (001), (e) (111), (f) (101), and (g) (100) surfaces, where $V_{O}^{x}$ denotes neutral oxygen vacancy and [ $]_{\mathrm{d}}$ denotes distorted cluster.

can be written as $V_{O}^{x}$ and has with a neutral charge. Therefore, the superficial clusters can be written as: $\left[\mathrm{MO}_{5} \cdot V_{O}^{x}\right]$, $\left[\mathrm{MO}_{4} \cdot 2 V_{O}^{x}\right]$, where $\mathrm{M}=\mathrm{Zn}$ and $\mathrm{W}$, and $\left[\mathrm{ZnO}_{3} \cdot 3 V_{O}^{x}\right]$. At the top of the (010) and (011) surfaces, there exist structural and distorted octahedral clusters called $\left[\mathrm{WO}_{6}\right]_{d}$, as shown in Figure 6.

\section{ELECTRONIC STRUCTURES AND PHOTO- CATALYTIC MECHANISM}

The physicochemical properties of materials are the manifestation of their electronic structure. In particular, the electronic band structure involving the valence position and the conduction band edges, and the Fermi level that can be tuned as a function of the morphology and composition of the materials. The Fermi level is considered as the total chemical or electrochemical potential for electrons, and its precise understanding is essential to relate the electronic band structure and the charge transfer characteristics in the materials ${ }^{190}$. The electronic structure of the different exposed surfaces was analyzed by calculating the density-of-states (DOS) functions and the band gap value.

The photocatalysts' electronic band structure, which is responsible for the photocatalysts, can be tuned using the specific exposed surfaces, which has significant impact on the redox abilities of photoinduced carries ${ }^{191}$. The DOS plots (total and projected on atoms) based on the DFT calculations for the (010), (110), (011), (001), (111), and (101) surfaces are shown in Figure 7.

$\mathrm{ZnWO}_{4}$ has a calculated (direct) band gap of $3.85 \mathrm{eV}$, which is comparable to the experimental value ${ }^{75}$. The analysis of the results revealed that the maximum VB is predominantly composed of the $\mathrm{O} 2 p$ states while the $\mathrm{CB}$ minimum is predominantly composed of the $\mathrm{W} 5 d$ states. 

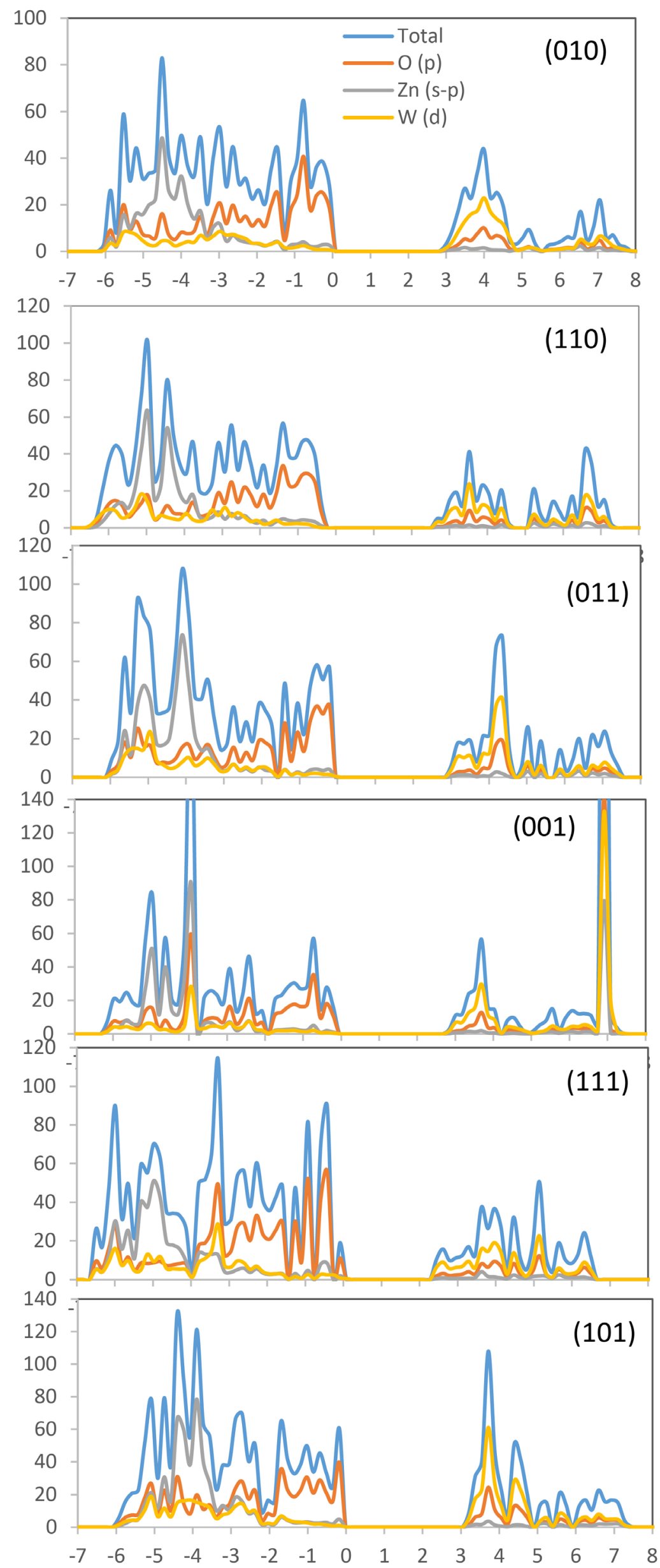

Figure 7. Density-of-states for (010), (110), (011), (001), (111), and (101) surfaces of $\mathrm{ZnWO}_{4}$. Fermi level is set to zero. 
Additionally, the figures show that the essential features of the different surfaces remain constant, but the more stable surfaces, i.e., (010), (110), and (011), exhibit a similar splitoff feature in the O $2 p$ and $\mathrm{W} 5 d$ partial DOS at the top of $\mathrm{VB}$ and bottom of $\mathrm{CB}$, where the transfer of electrons is produced to generate the $\mathrm{e}^{-} / \mathrm{h}^{+}$pairs.

The lack of reliable models that can describe the photocatalytic process is one of the biggest challenges toward achieving the long-term goal of optimizing the photocatalytic activity. The underlying mechanism is still heavily debated, but our proposed photocatalytic degradation mechanism, which is based on a comprehensive literature review $^{101,192-194}$ and the results of this study, is as follows: the first step is the absorption of light with energy equal to or greater than the band gap energy of the material. Consequently, the photon absorption causes the transfer of electrons $\left(\mathrm{e}^{-}\right)$from the VB to the $\mathrm{CB}$ and the subsequent generation of holes $\left(\mathrm{h}^{+}\right)$in the $\mathrm{VB}^{195}$. As shown in previous studies on $\mathrm{ZnWO}_{4}{ }^{58}$, electronic structure and polaron formation can provide crucial information on the electronic properties of complex transition-metal oxides ${ }^{196}$. In this context, Hoang et al. ${ }^{58}$ have shown that the electron polaron associated with the reduction of $\mathrm{W}^{6+}$ to $\mathrm{W}^{5+}$ is thus not stable in $\mathrm{ZnWO}_{4}$, that can be associated to their electronic structure in which there is a strong mixing between the $\mathrm{Zn} 3 d$ and $\mathrm{W}$ $5 d$ states at the CB maximum. As a result, an electron when added to the materials along the reduction process cannot be localized on any particular $\mathrm{W}$ cation and then the hole polaron, i.e. electron/hole $\left(\mathrm{e}^{-} / \mathrm{h}^{+}\right)$pairs are not formed and $\mathrm{ZnWO}_{4}$ are not active when used as pseudocapacitive electrode materials ${ }^{197}$.

The electrons in the $\mathrm{CB}$ and the holes in the VB exhibit high reducing and oxidizing power, respectively, and the migration of these charge-carriers $\left(\mathrm{e}^{-} / \mathrm{h}^{+}\right)$to the surface leads to oxidation. Additionally, the reduction reactions produce hydroxyl $(\mathrm{OH} \cdot)$ and superoxide $\left(\mathrm{O}_{2}{ }^{-{ }^{-}}\right)$radicals, respectively. The electron can react with molecular oxygen to produce superoxide anions $\left(\mathrm{O}_{2}{ }^{-}\right)$through a reductive process. The hole can abstract electrons from water and/or hydroxyl ions to generate hydroxyl radicals $(\mathrm{OH} \cdot)$ through an oxidative process ${ }^{198}$. Singlet oxygen $\left({ }^{1} \mathrm{O}_{2}\right)$ is mostly produced indirectly from the aqueous reactions of $\mathrm{O}_{2}{ }^{-195}$. Moreover, $\mathrm{OH} \cdot$ is a strong and non-selective oxidant that can damage virtually all types of organic biomolecules ${ }^{199}$. It is important to note that ${ }^{1} \mathrm{O}_{2}$ is the main mediator of photocytoxicity; it can irreversibly damage the treated tissues, and thus induce the oxidation and degradation of the biomembrane ${ }^{200,201}$. Moreover, as a precursor of $\mathrm{OH} \cdot$ and ${ }^{1} \mathrm{O}_{2}, \mathrm{O}_{2}{ }^{--}$is not a strong oxidant, although it plays a key role in the biological activi$\mathrm{ty}^{202}$.

The photocatalytic oxidization activities were evaluated by $\mathrm{RhB}$ degradation. Generally, the main oxidizing species were $\mathrm{OH} \cdot$ and $\mathrm{O}_{2}{ }^{\cdot}$ radicals ${ }^{203-205}$. The standard mechanism proposed by Zhang et al. for the photocatalytic reaction of the $\mathrm{ZnWO}_{4}$ is expressed as follows ${ }^{170}$ :

$$
\begin{aligned}
& \mathrm{ZnWO}_{4} \stackrel{\mathrm{h} \nu}{\rightarrow} \mathrm{ZnWO}_{4}\left(\mathrm{~h}^{+}\right)+\mathrm{ZnWO}_{4}\left(\mathrm{e}^{-}\right) \\
& \mathrm{O}_{2}+\mathrm{e}^{-} \rightarrow \mathrm{O}_{2} \\
& \mathrm{H}_{2} \mathrm{O}+\mathrm{h}^{+} \rightarrow \mathrm{H}^{+}+\mathrm{OH} \cdot
\end{aligned}
$$

Although many previous studies have investigated the photocatalytic mechanism, to the best of our knowledge, few studies have investigated the role of geometry and the electronic properties of the distorted octahedral $\left[\mathrm{ZnO}_{6}\right]$ and $\left[\mathrm{WO}_{6}\right]$ clusters at the exposed surfaces ${ }^{173}$ in the morphology (e.g., the under-coordination of both the $\mathrm{Zn}$ and $\mathrm{W}$ cations and electronic charge) during the ROS generation from $\mathrm{H}_{2} \mathrm{O}$ and $\mathrm{O}_{2}$. A deeper understanding of this aspect will allow us to interpret the underlying ROS generation mechanisms, potentially predict the amount of ROS generation or the photocatalytic activity of newly synthesized $\mathrm{ZnWO}_{4}$, and effectively reduce the costs of experimental testing.

A further challenge regards the very complicated electronic structures of the encountered $\mathrm{ZnWO}_{4}$, as is vividly illustrated by its naked exposed surfaces. To clarify the crucial factors affecting performance, a computational investigation was conducted to determine the relationship between the exposed clusters and the photocatalytic activity. To clarify the crucial factor affecting this correlation, the analysis of Figure 5, in particular the active (010) and (011) surfaces, elucidated the cause for the presence of $\left[\mathrm{ZnO}_{4}\right]$ and $\left[\mathrm{WO}_{6}\right]$ in at surface (010), and for the presence of $\left[\mathrm{ZnO}_{4}\right],\left[\mathrm{WO}_{5}\right]$, and $\left[\mathrm{WO}_{6}\right]$ at surface (011). The clusters were similar when the Kröger-Vink notation was used, and expressed as: $\left[\mathrm{ZnO}_{4}\right] \equiv\left[\mathrm{ZnO}_{4} \cdot 2 \mathrm{~V}_{O}^{x}\right],\left[\mathrm{WO}_{5}\right] \equiv\left[\mathrm{WO}_{5} \cdot \mathrm{V}_{O}^{x}\right]$ and $\left[\mathrm{WO}_{6}\right] \equiv\left[\mathrm{WO}_{6}\right]_{d}$ (Figure 6).

By examining Figure 6, it can be observed that there existed oxygen vacancies related with both the $\mathrm{W}$ and the $\mathrm{Zn}$ clusters. However, it should be emphasized that the $\mathrm{W}$ clusters formed the network because they were more stable. This stability resulted from the covalent nature of the $\mathrm{W}-\mathrm{O}$ bonds. Thus, in the formation of the electron/hole pairs that can be associated to a charge separation process with the concomitant formation of dipoles, the $\mathrm{W}$ clusters $\left[\mathrm{WO}_{6}\right]$, acted as electron receptors. Thus, the oxygen vacancies formed in the $\mathrm{Zn}$ clusters $\left[\mathrm{ZnO}_{4} \cdot 2 V_{O}{ }^{x}\right]$ or W clusters $\left[W \cdot V_{O}^{x}\right]$, and were capable of transferring electrons to the tungsten clusters $\left[\mathrm{WO}_{6}\right]$, and thus form permanent dipoles. Surfaces (010) and (011) were the most active in the photodegradation, owing to the appearance of these $\mathrm{W}$ and $\mathrm{Zn}$ clusters and the oxygen vacancies, which generated stable quantum dots. Thus, they were more likely to transfer the electron/hole to $\mathrm{O}_{2}$ and $\mathrm{H}_{2} \mathrm{O}$, respectively. In Table 1, these surfaces are those with a smaller $D_{\mathrm{b}}$ and different surface energies.

These two surfaces were unique surfaces amongst all of the low-index surfaces of the monoclinic $\mathrm{ZnWO}_{4}$ structure with both types of clusters at the top of the surface, as shown in Figure 6. In the lattice and superficial framework of the $\mathrm{ZnWO}_{4}$, there existed a cluster-to-cluster charge transfer process, which generated the electron/ hole pair responsible for the photocatalytic process. At the (010) exposed surface, these electronic rearrangements occurred from $\left[\mathrm{ZnO}_{4} \cdot 2 \mathrm{~V}_{\mathrm{O}}{ }^{x}\right]$ to $\left[\mathrm{WO}_{6}\right]_{d}$ and formed a negatively charged cluster $\left[W_{6}\right]_{d}{ }_{d}$, and a positively charged cluster $\left[\mathrm{ZnO}_{4} \cdot V_{O}{ }^{x} V_{O} \cdot\right]$, i.e., an electronic charge separation, as follows:

$$
\left[\mathrm{ZnO}_{4} \cdot 2 V_{O}{ }^{x}\right]+\left[\mathrm{WO}_{6}\right]_{d} \rightarrow\left[\mathrm{ZnO}_{4} \cdot V_{O}^{x} V_{O}{ }^{\cdot}\right]+\left[\mathrm{WO}_{6}\right]_{d}^{\prime}
$$

For the exposed (011) surface, the charge transfer process occurred from to: 


$$
\left[W O_{5} \cdot V_{O}^{x}\right]+\left[W O_{6}\right]_{d} \rightarrow\left[W O_{5} \cdot V_{O}^{*}\right]+\left[W O_{6}\right]_{d}^{\prime}
$$

where superscript $(x)$ indicates a neutral charge, symbol $(\bullet)$ corresponds to a positive charge, and a negative charge is denoted by symbol (') $)^{206}$, using the Kröger-Vink notation ${ }^{189}$.

Based on the analysis of the geometry and electronic properties for the exposed surface clusters, we hypothesize a detailed mechanism, wherein the structure-function relationship is clarified at the atomic level, in consistency with the DFT calculations presented above.

Therefore, along the photocatalytic mechanism, the $\mathrm{H}_{2} \mathrm{O}$ can react with the $\left[\mathrm{ZnO}_{4} \cdot \mathrm{V}_{\mathrm{O}}^{\mathrm{x}} \mathrm{V}_{\mathrm{O}}{ }^{\circ}\right]$ and/or $\left[\mathrm{WO}_{5} \cdot \mathrm{V}_{\mathrm{O}}{ }^{\circ}\right]$ cluster, while the $\mathrm{O}_{2}$ can react with the $\left[W O_{6}\right]_{d}^{\prime}$ cluster. In other words, the $\left[\mathrm{ZnO}_{4} \cdot \mathrm{V}_{O}^{\mathrm{x}} \mathrm{V}_{O}{ }^{\circ}\right]$ and/or $\left[\mathrm{WO}_{5} \cdot \mathrm{V}_{O}{ }^{\circ}\right]$ cluster are the sources of the holes, while the $\left[W O_{6}\right]_{d}^{\prime}$ cluster supplies the electron, which initiates the photocatalytic steps as follows:

$$
\begin{aligned}
& {\left[\mathrm{ZnO}_{4} \cdot \mathrm{V}_{\mathrm{O}}^{\mathrm{x}} \mathrm{V}_{\mathrm{O}}{ }^{*}\right]+\mathrm{H}_{2} \mathrm{O} \rightarrow \mathrm{OH}^{*}+\mathrm{H}^{\cdot}} \\
& {\left[\mathrm{WO}_{5} \cdot V_{\mathrm{O}}{ }^{\circ}\right]+\mathrm{H}_{2} \mathrm{O} \rightarrow \mathrm{OH}^{*}+\mathrm{H}^{\cdot}} \\
& {\left[\mathrm{WO}_{6}\right]_{d}^{\prime}+\mathrm{O}_{2} \rightarrow \mathrm{O}_{2}{ }^{\prime}}
\end{aligned}
$$

$\mathrm{O}_{2}{ }^{\prime}+\mathrm{OH}^{*}+\mathrm{RhB} \rightarrow \mathrm{CO}_{2}+\mathrm{H}_{2} \mathrm{O}+$ Degradation Products

The proposed mechanism for the photocatalytic reaction can also be expressed using the concept of the clusters appearing at the exposed surfaces, as an alternative to the standard mechanism proposed by Zhang et al. ${ }^{170}$, as follows:

$$
\left[\mathrm{ZnO}_{4}\right]+\left[\mathrm{WO}_{6}\right] \rightarrow\left[\mathrm{ZnO}_{4}\right]^{+}+\left[\mathrm{WO}_{6}\right]^{-}
$$

This step corresponds to the symmetry breaking process associated with an electronic change transfer with a concomitant formation of positive $\left[\mathrm{ZnO}_{4}\right]^{+}$, and negative $\left[\mathrm{WO}_{6}\right]$, centers that can be described with the formation of $\mathrm{h}^{+}$and $\mathrm{e}^{-}$, i.e., charge-carriers $\left(\mathrm{e}^{-} / \mathrm{h}^{+}\right)$, respectively. Considering the DOS analysis (Figure 7), we can conclude that the charge transfer process occurs from the $5 d$ and $3 d$ orbitals of both the $\mathrm{W}\left[\mathrm{WO}_{6}\right]$, and the $\mathrm{Zn}\left[\mathrm{ZnO}_{4}\right]$, centers at $\mathrm{CB}$, respectively, to the $2 p$ orbital of the $\mathrm{O}$ anions at the VB. Then, and act as $\mathrm{h}^{+}$and $\mathrm{e}^{-}$, respectively, as follows:

$$
\begin{aligned}
& {\left[\mathrm{ZnO}_{4}\right]^{+}+\mathrm{H}_{2} \mathrm{O} \rightarrow \mathrm{OH} \cdot+\mathrm{H}^{+}} \\
& {\left[\mathrm{WO}_{6}\right]^{-}+\mathrm{O}_{2} \rightarrow \mathrm{O}_{2}{ }^{-}}
\end{aligned}
$$

$\mathrm{O}_{2}{ }^{-}+\mathrm{OH} \bullet+R \mathrm{hB} \rightarrow \mathrm{CO}_{2}+\mathrm{H}_{2} \mathrm{O}+$ Degradation Products (14)

It is important to note that the remaining exposed surfaces do not exhibit under-coordinated clusters that are capable of generating electrons and holes with a tungstate cluster, i.e., an electron/hole pair, and thus prevent its participation in the photocatalytic mechanism. In summary, the presence of both the (010) and (011) surfaces in the morphology is a necessary condition for the $\mathrm{ZnWO}_{4}$ material to act as a photocatalyst, because only these exposed surfaces enable the presence of $\left[\mathrm{ZnO}_{4} \cdot 2 V_{O}{ }^{x}\right]$ (at the (010) surface) and $\left[W_{5} \cdot V_{O}{ }^{x}\right]$ (at the (011) surface) to act as electron donors to the adjacent $\left[W_{6}\right]_{d}$ clusters. This electronic charge process induces the formation of an electron/hole pair, wherein the $\left[\mathrm{ZnO}_{4} \cdot V_{O}^{{ }^{x}} V_{O}{ }^{\circ}\right] /\left[\mathrm{WO}_{5} \cdot V_{O}{ }^{\circ}\right]$ and $\left[\mathrm{WO}_{6}\right]^{\prime}{ }_{d}$ clusters are the active sites capable of reacting with $\mathrm{H}_{2} \mathrm{O}$ and $\mathrm{O}_{2}$, respectively, to initiate the photocatalytic mechanism.

\section{CONCLUSIONS AND OUTLOOK}

Chemical ordering, i.e., the arrangement of different species within a material, along with the size, morphology, and average composition, has a profound influence on optical, catalytic, and numerous other properties. In particular, research into controlling the morphology of micro- and nano-crystals is highly relevant to fields as diverse as materials science, catalysis, chemistry of materials, and nanotechnology. Computational studies provide an alternative approach to ward improving our fundamental understanding of solid morphologies and predicting the properties of novel materials with unusual exposed surfaces. Tuning the surface structure at the atomic level is of primary importance to simultaneously satisfy the catalytic performance and stability criteria required for the development of photocatalysts.

A comprehensive understanding of the origins of photocatalytic activity is often very difficult, and relies heavily on Edisonian trial-and-error processes, which lack adherence to theoretical and systematical guidelines and require the inclusion of other relevant factors. To this end, we attempt to address this question by applying density functional theory (DFT) simulations, and by verifying the results obtained from experimental data. Here, we present a consistent study on the structural, chemical and electronic properties of exposed $\mathrm{ZnWO}_{4}$ surfaces. The available morphologies of the materials are found using first-principle calculations, based on the Wulff constructions. Additionally, we explicitly unveil the exposed surfaces as a key factor that defines the photoactivity of $\mathrm{ZnWO}_{4}$.

As a proof of concept, the experimentally unknown key role of the structure and the electronic properties of the clusters, i.e., the local coordination of both the $\mathrm{Zn}$ and $\mathrm{W}$ cations located at the exposed surface, are highlighted. We report atomic details to clarify the influence of different exposed surfaces on the catalytic mechanism, which provides an atomic-level understanding of the geometric and electronic structures of their surfaces to comprehend, predict, and explain how catalytic properties emerge. The reliability of the proposed theoretical model was verified. Our simulations revealed that there exist two important factors that must be considered when investigating the surface electronic properties of $\mathrm{ZnWO}_{4}$. First, the (010) and (011) surfaces appear in all of the available morphologies with enhanced photocatalytic activity. The second factor is the specific local environment surrounding the site of interest, i.e., the cluster at the exposed surface. We found that the stability of the surfaces and their electronic properties are correlated with the presence of $\left[\mathrm{ZnO}_{4} \cdot 2 \mathrm{~V}_{O}{ }^{x}\right]$, $\left[\mathrm{WO}_{5}\right.$ $\left.\cdot V_{O}^{x}\right]$, and $\left[W O_{6}\right]_{d}$ clusters, and that reservoirs of electrons and holes, respectively, are active sites in the photocatalytic process. The structure-function correlation between the electronic properties and the morphology was investigated for $\mathrm{ZnWO}_{4}$.

The main conclusion drawn from this study is that both the intrinsic atomic properties and the electronic structure of the incomplete surface clusters, which appear at the exposed surfaces of the morphology, are required to explain the photocatalytic activity. These results indicate that the intrinsic atomic properties of metal oxide are controlled by the surface clusters present in the morphology. By computing the exposed surfaces and the available morphologies, we extracted an image of the effects exerted by the varying surface energy on 
the stability, morphology, and position of the Fermi level. We demonstrated that the morphological variations can induce significant changes in the electronic properties, and their relevance in various experimental manifestations. DFT links the latter phenomena to the structural and electronic disorder of under-coordinated clusters for both the $\mathrm{Zn}$ and $\mathrm{W}$ cations, which mimick an atomic recognition pattern that allows the identification of the local structure of active sites and the enhancement of catalytic performance. This study introduces a new approach toward thinking about $\mathrm{ZnWO}_{4}$ morphology, and provides a deep understanding of the relationship between the atomic structure and the electronic properties with regard to catalyst design.

Overall, the precise control of active sites on the exposed surfaces developed in this study represents a key step toward rational catalyst design, and provides a novel way of thinking that can be extrapolated to other semiconductors. For experimentalists, precise control with the on-demand manipulation of semiconductor morphology is of extreme interest. Ultimately, the bright future of semiconductors hinges upon the ability of the computational community to move from rationalizing to predicting materials, and the willingness of experimental researchers to take the resulting design principles on board. Our study provides fundamental and practical insights into the role of the surface structure and highlights strategies of designing more efficient photocatalysts. The predictive modeling approach proposed in this paper is general; therefore, it can be applied to other semiconductor structures and contribute to better-engineered materials in photocatalytic applications.

The process of photocatalysis involves the excitation of materials with the creation of electrons and holes, which points to the increasingly prominent role of electronic states other than the fundamental state. Therefore, work is in progress with regard to the modelling of electronic excited states for different exposed surfaces. The results of the ongoing investigations will be reported in the near future.

For future research in this field, to figure out exactly how molecules, in particular $\mathrm{O}_{2}, \mathrm{H}_{2} \mathrm{O}$ and ${ }^{1} \mathrm{O}_{2}$, and radicals, $\mathrm{OH} \cdot$ and $\mathrm{O}_{2}{ }^{-}$, interact with surfaces and with each other on diverse surfaces environment is still challenging, and a synergetic study including both experiment and theory is of critical importance. First, in order to characterize the intermediate states, more effort should focus on the surface local-structure analysis before and after the surface chemical reaction, and moreover the development of higher temporal and energy resolution techniques for in-site characterization of surface process is also needed. Second, based on structural analysis and in-situ measurement, a more quantitative quantum chemistry model beyond qualitative phenomenological model is hope to be developed. On this basis, a more precision and systematic surface chemical engineering strategy is expected. Third, as a remarkable outcome, the understanding that has been built on the structure-properties relationship would enable improved reliable stability and repeatability of surface chemistry modification, which are critical for promoting promising applications, and we are confident that, with the development of surface chemistry modulation, new breakthroughs in basic science.

\section{Acknowledgment}

This work was financially supported by Fundação de Amparo à Pesquisa do Estado de São Paulo (FAPESP 2013/07296-2), Conselho Nacional de Desenvolvimento Científico e Tecnológico (CNPq 150949/2018-9). Coordenação de Aperfeiçoamento de Pessoal de Nível Superior. J.A. acknowledges Universitat Jaume I, for project UJI-B2016-25, Generalitat Valenciana (Prometeo/ 2016/079, ACOMP/2015/1202), Ministerio de Economia y Competitividad, (Project No. CTQ2015-65207-P), and to the Spanish Brazilian program (PHBP14-00020). We also acknowledge the Servei Informatica, Universitat Jaume I for a generous allotment of computer time. The authors also wish to acknowledge Dr. L. Cabral (Federal University of São Carlos) for his generous help with the theoretical calculations.

\section{Notes}

The authors declare no competing financial interest.

\section{References}

[1]Mann S. The Chemistry of Form. Angewandte Chemie 2000;39:3392-406. doi: 10.1002/1521-3773(20001002)39:19<3392::aidanie3392>3.0.co;2-m

[2] Antonietti M, Ozin GA. Promises and Problems of Mesoscale Materials Chemistry or Why Meso? Chemistry - A European Journal 2004;10:28-41. doi:10.1002/chem.200305009

[3] Fermani S, Njegić Džakula B, Reggi M, Falini G, Kralj D. Effects of magnesium and temperature control on aragonite crystal aggregation and morphology. CrystEngComm 2017;19:2451-5. doi:10.1039/c7ce00197e

[4] Xiao X, Liu X, Zhao H, Chen D, Liu F, Xiang J, et al. Facile Shape Control of $\mathrm{Co}_{3} \mathrm{O}_{4}$ and the Effect of the Crystal Plane on Electrochemical Performance. Advanced Materials 2012;24:57626. doi:10.1002/adma.201202271

[5] Zhan Y, Shen L, Xu C, Zhao W, Cao Y, Jiang L. MOF-derived porous $\mathrm{Fe}_{2} \mathrm{O}_{3}$ with controllable shapes and improved catalytic activities in H2S selective oxidation. CrystEngComm 2018;20:344954. doi:10.1039/c8ce00552d

[6] Zhong Y, Wang Z, Zhang R, Bai F, Wu H, Haddad R, et al. Interfacial Self-Assembly Driven Formation of Hierarchically Structured Nanocrystals with Photocatalytic Activity. ACS Nano 2014;8:827-33. doi:10.1021/nn405492d

[7] Sinfelt JH. Role of surface science in catalysis. Surface Science 2002;500:923-46. doi:10.1016/s0039-6028(01)01532-1

[8] Olsson C-O., Landolt D. Passive films on stainless steelschemistry, structure and growth. Electrochimica Acta 2003;48:1093-104. doi:10.1016/s0013-4686(02)00841-1

[9] Wang Y-X, Robertson JL, Spillman, Jr. WB, Claus RO. Effects of the Chemical Structure and the Surface Properties of Polymeric Biomaterials on Their Biocompatibility. Pharmaceutical Research 2004;21:1362-73. doi:10.1023/b:pham.0000036909.41843.18

[10] Chen L-F, Feng Y, Liang H-W, Wu Z-Y, Yu S-H. Macroscopic-Scale Three-Dimensional Carbon Nanofiber Architectures for Electrochemical Energy Storage Devices. Advanced Energy Materials 2017;7:1700826. doi:10.1002/aenm.201700826

[11] Lukatskaya MR, Dunn B, Gogotsi Y. Multidimensional materials and device architectures for future hybrid energy storage. Nature Communications 2016;7. doi:10.1038/ncomms12647

[12] Oaki Y. Morphology Design of Crystalline and Polymer Materials from Nanoscopic to Macroscopic Scales. Bulletin of the Chemical Society of Japan 2017;90:776-88. doi:10.1246/ bcsj. 20170098 
[13] Wang K, Wu H, Meng Y, Wei Z. Conducting Polymer Nanowire Arrays for High Performance Supercapacitors. Small 2013;10:14-31. doi:10.1002/smll.201301991

[14] Wang Y, Arandiyan H, Scott J, Bagheri A, Dai H, Amal R. Recent advances in ordered meso/macroporous metal oxides for heterogeneous catalysis: a review. Journal of Materials Chemistry A 2017;5:8825-46. doi:10.1039/c6ta10896b

[15] Yeo SJ, Choi GH, Yoo PJ. Multiscale-architectured functional membranes utilizing inverse opal structures. Journal of Materials Chemistry A 2017;5:17111-34. doi:10.1039/c7ta05033j

[16] Sun CQ, Tay BK, Zeng XT, Li S, Chen TP, Zhou J, et al. Bond-order bond-length bond-strength (bond-OLS) correlation mechanism for the shape-and-size dependence of a nanosolid. Journal of Physics: Condensed Matter 2002;14:7781-95. doi:10.1088/0953-8984/14/34/301

[17] Burda C, Chen X, Narayanan R, El-Sayed MA. Chemistry and Properties of Nanocrystals of Different Shapes. Chemical Reviews 2005;105:1025-102. doi:10.1021/cr030063a

[18] Jia C-J, Schüth F. Colloidal metal nanoparticles as a component of designed catalyst. Physical Chemistry Chemical Physics 2011;13:2457. doi:10.1039/c0cp02680h

[19] Liu Y, Lai W, Yu T, Ma Y, Kang Y, Ge Z. Understanding the growth morphology of explosive crystals in solution: insights from solvent behavior at the crystal surface. RSC Advances 2017;7:1305-12. doi:10.1039/c6ra26920f

[20] Bi Y, Ouyang S, Umezawa N, Cao J, Ye J. Facet Effect of Single-Crystalline $\mathrm{Ag}_{3} \mathrm{PO}_{4}$ Sub-microcrystals on Photocatalytic Properties. Journal of the American Chemical Society 2011;133:64902. doi:10.1021/ja2002132

[21] Geng B, Fang C, Zhan F, Yu N. Synthesis of Polyhedral ZnS$\mathrm{nO}_{3}$ Microcrystals with Controlled Exposed Facets and Their Selective Gas-Sensing Properties. Small 2008;4:1337-43. doi:10.1002/ smll.200701177

[22] Li R, Zhang F, Wang D, Yang J, Li M, Zhu J, et al. Spatial separation of photogenerated electrons and holes among $\{010\}$ and $\{110\}$ crystal facets of $\mathrm{BiVO}_{4}$. Nature Communications 2013;4. doi:10.1038/ncomms2401

[23] Wang D, Jiang H, Zong X, Xu Q, Ma Y, Li G, et al. Crystal Facet Dependence of Water Oxidation on $\mathrm{BiVO}_{4}$ Sheets under Visible Light Irradiation. Chemistry - A European Journal 2010;17:127582. doi:10.1002/chem.201001636

[24] Zhong L-S, Hu J-S, Cao A-M, Liu Q, Song W-G, Wan L-J. 3D Flowerlike Ceria Micro/Nanocomposite Structure and Its Application for Water Treatment and CO Removal. Chemistry of Materials 2007;19:1648-55. doi:10.1021/cm062471b

[25] Tamvakos A, Korir K, Tamvakos D, Calestani D, Cicero G, Pullini D. $\mathrm{NO}_{2}$ Gas Sensing Mechanism of ZnO Thin-Film Transducers: Physical Experiment and Theoretical Correlation Study. ACS Sensors 2016;1:406-12. doi:10.1021/acssensors.6b00051

[26] Byzynski G, Melo C, Volanti DP, Ferrer MM, Gouveia AF, Ribeiro $\mathrm{C}$, et al. The interplay between morphology and photocatalytic activity in $\mathrm{ZnO}$ and $\mathrm{N}$-doped $\mathrm{ZnO}$ crystals. Materials \& Design 2017;120:363-75. doi:10.1016/j.matdes.2017.02.020

[27] Geng M, Jónsson H. Density functional theory calculations and thermodynamic analysis of bridgmanite surface structure. Physical Chemistry Chemical Physics 2019. doi:10.1039/ c8cp06702c

[28] Personick ML, Langille MR, Zhang J, Harris N, Schatz GC, Mirkin CA. Synthesis and Isolation of $\{110\}$-Faceted Gold Bipyramids and Rhombic Dodecahedra. Journal of the American Chemical Society 2011;133:6170-3. doi:10.1021/ja201826r

[29] Yu T, Kim DY, Zhang H, Xia Y. Platinum Concave Nanocubes with High-Index Facets and Their Enhanced Activity for Oxygen Reduction Reaction. Angewandte Chemie International Edition 2011;50:2773-7. doi:10.1002/anie.201007859

[30] Jiang Z-Y, Kuang Q, Xie Z-X, Zheng L-S. Syntheses and Properties of Micro/Nanostructured Crystallites with High-Energy Surfaces. Advanced Functional Materials 2010;20:3634-45. doi:10.1002/adfm.201001243

[31] Tao FF. Excavation of Precious-Metal-Based Alloy Nanoparticles for Efficient Catalysis. Angewandte Chemie International Edition 2016;55:15212-4. doi:10.1002/anie.201606324

[32] Tao FF. Excavation of Precious-Metal-Based Alloy Nanoparticles for Efficient Catalysis. Angewandte Chemie International Edition 2016;55:15212-4. doi:10.1002/anie.201606324

[33] Quan Z, Wang Y, Fang J. High-Index Faceted Noble Metal Nanocrystals. Accounts of Chemical Research 2012;46:191-202. doi:10.1021/ar200293n

[34] Zhang J, Kuang Q, Jiang Y, Xie Z. Engineering high-energy surfaces of noble metal nanocrystals with enhanced catalytic performances. Nano Today 2016;11:661-77. doi:10.1016/j.nantod.2016.08.012

[35] Vitos L, Ruban AV, Skriver HL, Kollár J. The surface energy of metals. Surface Science 1998;411:186-202. doi:10.1016/s00396028(98)00363-X

[36] Kang Y, Li M, Cai Y, Cargnello M, Diaz RE, Gordon TR, et al. Heterogeneous Catalysts Need Not Be so "Heterogeneous": Monodisperse Pt Nanocrystals by Combining Shape-Controlled Synthesis and Purification by Colloidal Recrystallization. Journal of the American Chemical Society 2013;135:2741-7. doi:10.1021/ ja3116839

[37] Lee C-T, Yang X, Vara M, Gilroy KD, Xia Y. Water-Based Synthesis of Sub-10 nm Pt Octahedra and Their Performance towards the Oxygen Reduction Reaction. ChemNanoMat 2017;3:879-84. doi:10.1002/cnma.201700189

[38] Song H, Kim F, Connor S, Somorjai GA, Yang P. Pt Nanocrystals: Shape Control and Langmuir-Blodgett Monolayer Formation. The Journal of Physical Chemistry B 2005;109:188-93. doi:10.1021/jp0464775

[39] Demortière A, Launois P, Goubet N, Albouy P-A, Petit C. Shape-Controlled Platinum Nanocubes and Their Assembly into Two-Dimensional and Three-Dimensional Superlattices $\dagger$. The Journal of Physical Chemistry B 2008;112:14583-92. doi:10.1021/ jp802081n

[40] Liao H-G, Zherebetskyy D, Xin H, Czarnik C, Ercius P, Elmlund $\mathrm{H}$, et al. Facet development during platinum nanocube growth. Science 2014;345:916-9. doi:10.1126/science.1253149

[41] Ren J, Tilley RD. Preparation, Self-Assembly, and Mechanistic Study of Highly Monodispersed Nanocubes. Journal of the American Chemical Society 2007;129:3287-91. doi:10.1021/ja067636w

[42] Wang C, Daimon H, Lee Y, Kim J, Sun S. Synthesis of Monodisperse Pt Nanocubes and Their Enhanced Catalysis for Oxygen Reduction. Journal of the American Chemical Society 2007;129:6974-5. doi:10.1021/ja070440r

[43] Wu B, Zheng N, Fu G. Small molecules control the formation of Pt nanocrystals: a key role of carbon monoxide in the synthesis of Pt nanocubes. Chem Commun 2011;47:1039-41. doi:10.1039/ c0cc03671d

[44] Kang Y, Pyo JB, Ye X, Diaz RE, Gordon TR, Stach EA, et al. Shape-Controlled Synthesis of Pt Nanocrystals: The Role of Metal Carbonyls. ACS Nano 2012;7:645-53. doi:10.1021/nn3048439

[45] Lim SI, Ojea-Jiménez I, Varon M, Casals E, Arbiol J, Puntes V. Synthesis of Platinum Cubes, Polypods, Cuboctahedrons, and Raspberries Assisted by Cobalt Nanocrystals. Nano Letters 
2010;10:964-73. doi:10.1021/nl100032c

[46] Tian N, Zhou Z-Y, Sun S-G. Platinum Metal Catalysts of High-Index Surfaces: From Single-Crystal Planes to Electrochemically Shape-Controlled Nanoparticles. The Journal of Physical Chemistry C 2008;112:19801-17. doi:10.1021/jp804051e

[47] Druce J, Téllez H, Burriel M, Sharp MD, Fawcett LJ, Cook $\mathrm{SN}$, et al. Surface termination and subsurface restructuring of perovskite-based solid oxide electrode materials. Energy Environ Sci 2014;7:3593-9. doi:10.1039/c4ee01497a

[48] Staykov A, Téllez H, Akbay T, Druce J, Ishihara T, Kilner J. Oxygen Activation and Dissociation on Transition Metal Free Perovskite Surfaces. Chemistry of Materials 2015;27:8273-81. doi:10.1021/acs.chemmater.5b03263

[49] Staykov A, Tellez H, Druce J, Wu J, Ishihara T, Kilner J. Electronic properties and surface reactivity of SrO-terminated $\mathrm{SrTiO}_{3}$ and SrO-terminated iron-doped $\mathrm{SrTiO}_{3}$. Science and Technology of Advanced Materials 2018;19:221-30. doi:10.1080/14686996.201 8.1440136

[50] Huang K, Yuan L, Feng S. Crystal facet tailoring arts in perovskite oxides. Inorganic Chemistry Frontiers 2015;2:965-81. doi:10.1039/c5qi00168d

[51] Salehi G, Abazari R, Mahjoub AR. Visible-Light-Induced Graphitic-C3N4@Nickel-Aluminum Layered Double Hydroxide Nanocomposites with Enhanced Photocatalytic Activity for Removal of Dyes in Water. Inorganic Chemistry 2018;57:8681-91. doi:10.1021/acs.inorgchem.8b01636

[52] Dai X, Han Z, Waterhouse GIN, Fan H, Ai S. Ordered graphitic carbon nitride tubular bundles with efficient electron-hole separation and enhanced photocatalytic performance for hydrogen generation. Applied Catalysis A: General 2018;566:200-6. doi:10.1016/j.apcata.2018.09.001

[53] Santanna MA, Menezes WT, Santana YVB, Ferrer MM, Gouveia $\mathrm{AF}$, Faceto $\mathrm{AD}$, et al. The effect of $\mathrm{TiO}_{2}$ nanotube morphological engineering and $\mathrm{ZnS}$ quantum dots on the water splitting reaction: A theoretical and experimental study. International Journal of Hydrogen Energy 2018;43:6838-50. doi:10.1016/ j.ijhydene.2018.02.113

[54] Zhang A-Y, Wang W-Y, Chen J-J, Liu C, Li Q-X, Zhang X, et al. Epitaxial facet junctions on $\mathrm{TiO}_{2}$ single crystals for efficient photocatalytic water splitting. Energy \& Environmental Science 2018;11:1444-8. doi:10.1039/c7ee03482b

[55] Quek J-A, Lam S-M, Sin J-C, Mohamed AR. Visible light responsive flower-like $\mathrm{ZnO}$ in photocatalytic antibacterial mechanism towards Enterococcus faecalis and Micrococcus luteus. Journal of Photochemistry and Photobiology B: Biology 2018;187:6675. doi:10.1016/j.jphotobiol.2018.07.030

[56] Yin Q, Tan L, Lang Q, Ke X, Bai L, Guo K, et al. Plasmonic molybdenum oxide nanosheets supported silver nanocubes for enhanced near-infrared antibacterial activity: Synergism of photothermal effect, silver release and photocatalytic reactions. Applied Catalysis B: Environmental 2018;224:671-80. doi:10.1016/j.apcatb.2017.11.024

[57] Wang C, Daimon H, Onodera T, Koda T, Sun S. A General Approach to the Size- and Shape-Controlled Synthesis of Platinum Nanoparticles and Their Catalytic Reduction of Oxygen. Angewandte Chemie International Edition 2008;47:3588-91. doi:10.1002/anie.200800073

[58] Hoang K, Oh M, Choi Y. Electronic structure, polaron formation, and functional properties in transition-metal tungstates. RSC Advances 2018;8:4191-6. doi:10.1039/c7ra13436c

[59] Bai S, Wang L, Li Z, Xiong Y. Facet-Engineered Surface and Interface Design of Photocatalytic Materials. Advanced Science
2016;4:1600216. doi:10.1002/advs.201600216

[60] Huang H, Tu S, Zeng C, Zhang T, Reshak AH, Zhang Y. Macroscopic Polarization Enhancement Promoting Photo- and Piezoelectric-Induced Charge Separation and Molecular Oxygen Activation. Angewandte Chemie 2017;129:12022-6. doi:10.1002/ ange.201706549

[61] Huang H, Wang J, Dong F, Guo Y, Tian N, Zhang Y, et al. Highly Efficient $\mathrm{Bi}_{2} \mathrm{O}_{2} \mathrm{CO}_{3}$ Single-Crystal Lamellas with Dominantly Exposed \{001\} Facets. Crystal Growth \& Design 2015;15:534-7. doi:10.1021/cg501527k

[62] Huang H, He Y, Li X, Li M, Zeng C, Dong F, et al. $\mathrm{Bi}_{2} \mathrm{O}_{2}(\mathrm{OH})$ $\left(\mathrm{NO}_{3}\right)$ as a desirable $\left[\mathrm{Bi}_{2} \mathrm{O}_{2}\right]^{2+}$ layered photocatalyst: strong intrinsic polarity, rational band structure and $\{001\}$ active facets co-beneficial for robust photooxidation capability. Journal of Materials Chemistry A 2015;3:24547-56. doi:10.1039/c5ta07655b

[63] Xie YP, Liu G, Yin L, Cheng H-M. Crystal facet-dependent photocatalytic oxidation and reduction reactivity of monoclinic $\mathrm{WO}_{3}$ for solar energy conversion. Journal of Materials Chemistry 2012;22:6746. doi:10.1039/c2jm16178h

[64] Xu H, Ouyang S, Li P, Kako T, Ye J. High-Active Anatase $\mathrm{TiO}_{2}$ Nanosheets Exposed with 95\% \{100\} Facets Toward Efficient H2 Evolution and $\mathrm{CO}_{2}$ Photoreduction. ACS Applied Materials \& Interfaces 2013;5:1348-54. doi:10.1021/am302631b

[65] Wang J, Bian Z, Zhu J, Li H. Ordered mesoporous $\mathrm{TiO}_{2}$ with exposed (001) facets and enhanced activity in photocatalytic selective oxidation of alcohols. J Mater Chem A 2013;1:1296-302. doi:10.1039/c2ta00035k

[66] Mclaren A, Valdes-Solis T, Li G, Tsang SC. Shape and Size Effects of ZnO Nanocrystals on Photocatalytic Activity. Journal of the American Chemical Society 2009;131:12540-1. doi:10.1021/ ja9052703

[67] Xi G, Ye J. Synthesis of bismuth vanadate nanoplates with exposed $\{001\}$ facets and enhanced visible-light photocatalytic properties. Chemical Communications 2010;46:1893. doi:10.1039/ b923435g

[68] Li G, Yi Z, Bai Y, Zhang W, Zhang H. Anisotropy in photocatalytic oxidization activity of $\mathrm{NaNbO}_{3}$ photocatalyst. Dalton Transactions 2012;41:10194. doi:10.1039/c2dt30593c

[69] Liu S, Yu J, Jaroniec M. Tunable Photocatalytic Selectivity of Hollow $\mathrm{TiO}_{2}$ Microspheres Composed of Anatase Polyhedra with Exposed $\{001\}$ Facets. Journal of the American Chemical Society 2010;132:11914-6. doi:10.1021/ja105283s

[70] Gong H, Ma R, Mao F, Liu K, Cao H, Yan H. Light-induced spatial separation of charges toward different crystal facets of square-like $\mathrm{WO}_{3}$. Chemical Communications 2016;52:11979-82. doi:10.1039/c6cc06363b

[71] Meng J, Lan Z, Lin Q, Chen T, Chen X, Wei X, et al. Cubic-like $\mathrm{BaZrO}_{3}$ nanocrystals with exposed $\{001\} /\{011\}$ facets and tuned electronic band structure for enhanced photocatalytic hydrogen production. Journal of Materials Science 2018;54:1967-76. doi:10.1007/s10853-018-2995-8

[72] Trench AB, Machado TR, Gouveia AF, Assis M, da Trindade LG, Santos C, et al. Connecting structural, optical, and electronic properties and photocatalytic activity of $\mathrm{Ag}_{3} \mathrm{PO}_{4}$ :Mo complemented by DFT calculations. Applied Catalysis B: Environmental 2018;238:198-211. doi:10.1016/j.apcatb.2018.07.019

[73] Macedo NG, Gouveia AF, Roca RA, Assis M, Gracia L, Andrés J, et al. Surfactant-Mediated Morphology and Photocatalytic Activity of $\alpha-\mathrm{Ag}_{2} \mathrm{WO}_{4}$ Material. The Journal of Physical Chemistry C 2018;122:8667-79. doi:10.1021/acs.jpcc.8b01898

[74] Bomio MRD, Tranquilin RL, Motta FV, Paskocimas CA, Nascimento RM, Gracia L, et al. Toward Understanding the 
Photocatalytic Activity of $\mathrm{PbMoO}_{4}$ Powders with Predominant (111), (100), (011), and (110) Facets. A Combined Experimental and Theoretical Study. The Journal of Physical Chemistry C 2013;117:21382-95. doi:10.1021/jp407416h

[75] Pereira PFS, Gouveia AF, Assis M, de Oliveira RC, Pinatti IM, Penha M, et al. $\mathrm{ZnWO}_{4}$ nanocrystals: synthesis, morphology, photoluminescence and photocatalytic properties. Physical Chemistry Chemical Physics 2018;20:1923-37. doi:10.1039/C7CP07354B

[76] Rosal FJO, Gouveia AF, Sczancoski JC, Lemos PS, Longo E, Zhang B, et al. Electronic structure, growth mechanism, and sonophotocatalytic properties of sphere-like self-assembled $\mathrm{NiWO}_{4}$ nanocrystals. Inorganic Chemistry Communications 2018;98:3440. doi:10.1016/j.inoche.2018.10.001

[77] Zamperini CA, André RS, Longo VM, Mima EG, Vergani $\mathrm{CE}$, Machado AL, et al. Antifungal Applications of Ag-Decorated Hydroxyapatite Nanoparticles. Journal of Nanomaterials 2013;2013:1-9. doi:10.1155/2013/174398

[78] Longo VM, De Foggi CC, Ferrer MM, Gouveia AF, André RS, Avansi W, et al. Potentiated Electron Transference in $\alpha-\mathrm{Ag}_{2} \mathrm{WO}_{4}$ Microcrystals with Ag Nanofilaments as Microbial Agent. The Journal of Physical Chemistry A 2014;118:5769-78. doi:10.1021/ jp410564p

[79] Foggi CC, Fabbro MT, Santos LPS, de Santana YVB, Vergani $\mathrm{CE}$, Machado AL, et al. Synthesis and evaluation of $\alpha-\mathrm{Ag}_{2} \mathrm{WO}_{4}$ as novel antifungal agent. Chemical Physics Letters 2017;674:125-9. doi:10.1016/j.cplett.2017.02.067

[80] De Oliveira RC, de Foggi CC, Teixeira MM, da Silva MDP, Assis M, Francisco EM, et al. Mechanism of Antibacterial Activity via Morphology Change of $\alpha-\mathrm{AgVO}_{3}$ : Theoretical and Experimental Insights. ACS Applied Materials \& Interfaces 2017;9:11472-81. doi:10.1021/acsami.7b00920

[81] Assis M, Cordoncillo E, Torres-Mendieta R, Beltrán-Mir H, Mínguez-Vega G, Oliveira R, et al. Towards the scale-up of the formation of nanoparticles on $\alpha-\mathrm{Ag}_{2} \mathrm{WO}_{4}$ with bactericidal properties by femtosecond laser irradiation. Scientific Reports 2018;8. doi:10.1038/s41598-018-19270-9

[82] Xu Q, Zhang L, Yu J, Wageh S, Al-Ghamdi AA, Jaroniec M. Direct Z-scheme photocatalysts: Principles, synthesis, and applications. Materials Today 2018;21:1042-63. doi:10.1016/j.mattod.2018.04.008

[83] Moniz SJA, Shevlin SA, Martin DJ, Guo Z-X, Tang J. Visible-light driven heterojunction photocatalysts for water splitting a critical review. Energy \& Environmental Science 2015;8:731-59. doi:10.1039/C4EE03271C

[84] Li R, Zhang F, Wang D, Yang J, Li M, Zhu J, et al. Spatial separation of photogenerated electrons and holes among $\{010\}$ and $\{110\}$ crystal facets of $\mathrm{BiVO}_{4}$. Nature Communications 2013;4. doi:10.1038/ncomms2401

[85] Hameed A, Montini T, Gombac V, Fornasiero P. Surface Phases and Photocatalytic Activity Correlation of $\mathrm{Bi}_{2} \mathrm{O}_{3} /$ $\mathrm{Bi}_{2} \mathrm{O}_{4}$-xNanocomposite. Journal of the American Chemical Society 2008;130:9658-9. doi:10.1021/ja803603y

[86] Zhang J, Xu Q, Feng Z, Li M, Li C. Importance of the Relationship between Surface Phases and Photocatalytic Activity of $\mathrm{TiO}_{2}$. Angewandte Chemie International Edition 2008;47:1766-9. doi:10.1002/anie.200704788

[87] Emin D. Polarons 2012. doi:10.1017/CBO9781139023436

[88] Han Z, Wang N, Fan H, Ai S. Ag nanoparticles loaded on porous graphitic carbon nitride with enhanced photocatalytic activity for degradation of phenol. Solid State Sciences 2017;65:110-5. doi:10.1016/j.solidstatesciences.2017.01.010

[89] Liu C, Kong D, Hsu P-C, Yuan H, Lee H-W, Liu Y, et al. Rap- id water disinfection using vertically aligned $\mathrm{MoS}_{2}$ nanofilms and visible light. Nature Nanotechnology 2016;11:1098-104. doi:10.1038/nnano.2016.138

[90] Yu F, Cao L, Huang J, Wu J. Effects of $\mathrm{pH}$ on the microstructures and optical property of $\mathrm{FeWO}_{4}$ nanocrystallites prepared via hydrothermal method. Ceramics International 2013;39:4133-8. doi:10.1016/j.ceramint.2012.10.269

[91] Zhang J, Xia J, Yin S, Li H, Xu H, He M, et al. Improvement of visible light photocatalytic activity over flower-like $\mathrm{BiOCl} /$ BiOBr microspheres synthesized by reactable ionic liquids. Colloids and Surfaces A: Physicochemical and Engineering Aspects 2013;420:89-95. doi:10.1016/j.colsurfa.2012.11.054

[92] Zhang X, Ji G, Liu Y, Zhou X, Zhu Y, Shi D, et al. The role of Sn in enhancing the visible-light photocatalytic activity of hollow hierarchical microspheres of the $\mathrm{Bi} / \mathrm{BiOBr}$ heterojunction. Physical Chemistry Chemical Physics 2015;17:8078-86. doi:10.1039/ C5CP00184F

[93] Liu Z, Niu J, Feng P, Sui Y, Zhu Y. One-pot synthesis of $\mathrm{Bi}_{2} 4 \mathrm{O}$ ${ }_{3} 1 \mathrm{Br} 10 / \mathrm{Bi} 4 \mathrm{~V} 2 \mathrm{O} 11$ heterostructures and their photocatalytic properties. RSC Adv 2014;4:43399-405. doi:10.1039/C4RA04815F

[94] Wu X, Ng YH, Wang L, Du Y, Dou SX, Amal R, et al. Improving the photo-oxidative capability of $\mathrm{BiOBr}$ via crystal facet engineering. Journal of Materials Chemistry A 2017;5:8117-24. doi:10.1039/C6TA10964K

[95] Liu G, Yu JC, Lu GQ (Max), Cheng H-M. Crystal facet engineering of semiconductor photocatalysts: motivations, advances and unique properties. Chemical Communications 2011;47:6763. doi:10.1039/c1cc10665a

[96] Liu G, Yang HG, Pan J, Yang YQ, Lu GQ (Max), Cheng H-M. Titanium Dioxide Crystals with Tailored Facets. Chemical Reviews 2014;114:9559-612. doi:10.1021/cr400621z

[97] Wu Z, Xue Y, Zou Z, Wang X, Gao F. Single-crystalline titanium dioxide hollow tetragonal nanocones with large exposed (101) facets for excellent photocatalysis. Journal of Colloid and Interface Science 2017;490:420-9. doi:10.1016/j.jcis.2016.11.077

[98] Yuan D, Zhang L, Lai J, Xie L, Mao B, Zhan D. SECM evaluations of the crystal-facet-correlated photocatalytic activity of hematites for water splitting. Electrochemistry Communications 2016;73:29-32. doi:10.1016/j.elecom.2016.10.011

[99] Qi W, An X, Zhang F, Liu H, Qu J. Facet-dependent intermediate formation and reaction mechanism of photocatalytic removing hydrophobic anthracene under simulated solar irradiation. Applied Catalysis B: Environmental 2017;206:194-202. doi:10.1016/j.apcatb.2017.01.018

[100] Rong S, Zhang P, Liu F, Yang Y. Engineering Crystal Facet of $\alpha-\mathrm{MnO}_{2}$ Nanowire for Highly Efficient Catalytic Oxidation of Carcinogenic Airborne Formaldehyde. ACS Catalysis 2018;8:3435-46. doi:10.1021/acscatal.8b00456

[101] Li Y, Zhang W, Niu J, Chen Y. Mechanism of Photogenerated Reactive Oxygen Species and Correlation with the Antibacterial Properties of Engineered Metal-Oxide Nanoparticles. ACS Nano 2012;6:5164-73. doi:10.1021/nn300934k

[102] Gao R, Zhu J, Xiao X, Hu Z, Liu J, Liu X. Facet-Dependent Electrocatalytic Performance of $\mathrm{Co}_{3} \mathrm{O}_{4}$ for Rechargeable $\mathrm{Li}-\mathrm{O}_{2}$ Battery. The Journal of Physical Chemistry C 2015;119:4516-23. doi:10.1021/jp511363p

[103] Guo C, Zheng Y, Ran J, Xie F, Jaroniec M, Qiao S-Z. Engineering High-Energy Interfacial Structures for High-Performance Oxygen-Involving Electrocatalysis. Angewandte Chemie International Edition 2017;56:8539-43. doi:10.1002/anie.201701531

[104] Stoerzinger KA, Diaz-Morales O, Kolb M, Rao RR, Frydendal R, Qiao L, et al. Orientation-Dependent Oxygen Evolution on 
$\mathrm{RuO}_{2}$ without Lattice Exchange. ACS Energy Letters 2017;2:87681. doi:10.1021/acsenergylett.7b00135

[105] Tung C-W, Hsu Y-Y, Shen Y-P, Zheng Y, Chan T-S, Sheu H-S, et al. Reversible adapting layer produces robust single-crystal electrocatalyst for oxygen evolution. Nature Communications 2015;6. doi:10.1038/ncomms9106

[106] Wu T, Stone ML, Shearer MJ, Stolt MJ, Guzei IA, Hamers RJ, et al. Crystallographic Facet Dependence of the Hydrogen Evolution Reaction on CoPS: Theory and Experiments. ACS Catalysis 2018;8:1143-52. doi:10.1021/acscatal.7b03167

[107] Gao C, Meng Q, Zhao K, Yin H, Wang D, Guo J, et al. $\mathrm{Co}_{3} \mathrm{O}-$ ${ }_{4}$ Hexagonal Platelets with Controllable Facets Enabling Highly Efficient Visible-Light Photocatalytic Reduction of $\mathrm{CO}_{2}$. Advanced Materials 2016;28:6485-90. doi:10.1002/adma.201601387

[108] Hou Y, Wang D, Yang XH, Fang WQ, Zhang B, Wang HF, et al. Rational screening low-cost counter electrodes for dye-sensitized solar cells. Nature Communications 2013;4. doi:10.1038/ ncomms 2547

[109] Li C, Koenigsmann C, Ding W, Rudshteyn B, Yang KR, Regan KP, et al. Facet-Dependent Photoelectrochemical Performance of $\mathrm{TiO}_{2}$ Nanostructures: An Experimental and Computational Study. Journal of the American Chemical Society 2015;137:15209. doi:10.1021/ja5111078

[110] Stoerzinger KA, Qiao L, Biegalski MD, Shao-Horn Y. Orientation-Dependent Oxygen Evolution Activities of Rutile $\mathrm{IrO}_{2}$ and $\mathrm{RuO}_{2}$. The Journal of Physical Chemistry Letters 2014;5:1636-41. doi:10.1021/jz500610u

[111] Yang HG, Sun CH, Qiao SZ, Zou J, Liu G, Smith SC, et al. Anatase $\mathrm{TiO}_{2}$ single crystals with a large percentage of reactive facets. Nature 2008;453:638-41. doi:10.1038/nature06964

[112] Yang HG, Liu G, Qiao SZ, Sun CH, Jin YG, Smith SC, et al. Solvothermal Synthesis and Photoreactivity of Anatase $\mathrm{TiO}_{2} \mathrm{~N}$ anosheets with Dominant $\{001\}$ Facets. Journal of the American Chemical Society 2009;131:4078-83. doi:10.1021/ja808790p

[113] Han X, Kuang Q, Jin M, Xie Z, Zheng L. Synthesis of Titania Nanosheets with a High Percentage of Exposed (001) Facets and Related Photocatalytic Properties. Journal of the American Chemical Society 2009;131:3152-3. doi:10.1021/ja8092373

[114] Sun L, Qin Y, Cao Q, Hu B, Huang Z, Ye L, et al. Novel photocatalytic antibacterial activity of $\mathrm{TiO}_{2}$ microspheres exposing $100 \%$ reactive $\{111\}$ facets. Chemical Communications 2011;47:12628. doi:10.1039/c1cc15350a

[115] Lazzeri M, Vittadini A, Selloni A. Erratum: Structure and energetics of stoichiometric $\mathrm{TiO}_{2}$ anatase surfaces. Physical Review B 2002;65. doi:10.1103/physrevb.65.119901

[116] Wen CZ, Zhou JZ, Jiang HB, Hu QH, Qiao SZ, Yang HG. Synthesis of micro-sized titanium dioxide nanosheets wholly exposed with high-energy $\{001\}$ and $\{100\}$ facets. Chemical Communications 2011;47:4400. doi:10.1039/c0cc05798c

[117] Pan J, Wu X, Wang L, Liu G, Lu GQ (Max), Cheng H-M. Synthesis of anatase $\mathrm{TiO}_{2}$ rods with dominant reactive $\{010\}$ facets for the photoreduction of $\mathrm{CO}_{2}$ to $\mathrm{CH}_{4}$ and use in dye-sensitized solar cells. Chemical Communications 2011;47:8361. doi:10.1039/ c1cc13034j

[118] Carey JJ, McKenna KP. Does Polaronic Self-Trapping Occur at Anatase $\mathrm{TiO}_{2}$ Surfaces? The Journal of Physical Chemistry C 2018;122:27540-53. doi:10.1021/acs.jpcc.8b09437

[119] Guo S, Zhang S, Sun S. Tuning Nanoparticle Catalysis for the Oxygen Reduction Reaction. Angewandte Chemie International Edition 2013;52:8526-44. doi:10.1002/anie.201207186

[120] Xie S, Choi S-I, Xia X, Xia Y. Catalysis on faceted noble-metal nanocrystals: both shape and size matter. Current Opinion in Chemical Engineering 2013;2:142-50. doi:10.1016/j.coche.2013.02.003

[121] Bratlie KM, Kliewer CJ, Somorjai GA. Structure Effects of Benzene Hydrogenation Studied with Sum Frequency Generation Vibrational Spectroscopy and Kinetics on Pt(111) and $\mathrm{Pt}(100)$ Single-Crystal Surfaces. The Journal of Physical Chemistry B 2006;110:17925-30. doi:10.1021/jp062623q

[122] Mostafa S, Behafarid F, Croy JR, Ono LK, Li L, Yang JC, et al. Shape-Dependent Catalytic Properties of Pt Nanoparticles. Journal of the American Chemical Society 2010;132:15714-9. doi:10.1021/ja106679z

[123] Lee I, Morales R, Albiter MA, Zaera F. Synthesis of heterogeneous catalysts with well shaped platinum particles to control reaction selectivity. Proceedings of the National Academy of Sciences 2008;105:15241-6. doi:10.1073/pnas.0805691105

[124] Tian N, Zhou Z-Y, Sun S-G, Ding Y, Wang ZL. Synthesis of Tetrahexahedral Platinum Nanocrystals with High-Index Facets and High Electro-Oxidation Activity. Science 2007;316:732-5. doi:10.1126/science.1140484

[125] Schneer C. Pierre Curie: On the formation of crystals and capillary constants of their different faces. Journal of Chemical Education 1970;47:636. doi:10.1021/ed047p636

[126] Abendan RS, Swift JA. Dissolution on Cholesterol Monohydrate Single-Crystal Surfaces Monitored by in Situ Atomic Force Microscopy $\dagger$. Crystal Growth \& Design 2005;5:2146-53. doi:10.1021/cg050236k

[127] Herring C. Some Theorems on the Free Energies of Crystal Surfaces. Physical Review 1951;82:87-93. doi:10.1103/physrev.82.87

[128] Mordehai D, Rabkin E, Srolovitz DJ. Pseudoelastic Deformation during Nanoscale Adhesive Contact Formation. Physical Review Letters 2011;107. doi:10.1103/PhysRevLett.107.096101

[129] Barmparis GD, Remediakis IN. Dependence on CO adsorption of the shapes of multifaceted gold nanoparticles: A density functional theory. Physical Review B 2012;86. doi:10.1103/PhysRevB.86.085457

[130] Barmparis GD, Lodziana Z, Lopez N, Remediakis IN. Nanoparticle shapes by using Wulff constructions and first-principles calculations. Beilstein Journal of Nanotechnology 2015;6:361-8. doi:10.3762/bjnano.6.35

[131] Andrés J, Gracia L, Gouveia AF, Ferrer MM, Longo E. Effects of surface stability on the morphological transformation of metals and metal oxides as investigated by first-principles calculations. Nanotechnology 2015;26:405703. doi:10.1088/09574484/26/40/405703

[132] Ferrer MM, Gouveia AF, Gracia L, Longo E, Andrés J. A 3D platform for the morphology modulation of materials: first principles calculations on the thermodynamic stability and surface structure of metal oxides: $\mathrm{Co}_{3} \mathrm{O}_{4}, \alpha-\mathrm{Fe}_{2} \mathrm{O}_{3}$, and $\operatorname{In}_{2} \mathrm{O}_{3}$. Modelling and Simulation in Materials Science and Engineering 2016;24:025007. doi:10.1088/0965-0393/24/2/025007

[133] Gouveia AF, Ferrer MM, Sambrano JR, Andrés J, Longo E. Modeling the atomic-scale structure, stability, and morphological transformations in the tetragonal phase of $\mathrm{LaVO}_{4}$. Chemical Physics Letters 2016;660:87-92. doi:10.1016/j.cplett.2016.08.013

[134] Barbosa M de A, Fabris G da SL, Ferrer MM, Azevedo DHM de, Sambrano JR. Computational Simulations of Morphological Transformations by Surface Structures: The Case of Rutile $\mathrm{TiO}_{2}$ phase. Materials Research 2017;20:920-5. doi:10.1590/1980-5373mr-2016-0709

[135] Geysermans P, Finocchi F, Goniakowski J, Hacquart R, Jupille J. Combination of (100), (110) and (111) facets in MgO 
crystals shapes from dry to wet environment. Physical Chemistry Chemical Physics 2009;11:2228. doi:10.1039/b812376d

[136] Yao Y, Wei Y, Chen S. Size effect of the surface energy density of nanoparticles. Surface Science 2015;636:19-24. doi:10.1016/ j.susc.2015.01.016

[137] Oliveira MC, Gracia L, Nogueira IC, Carmo Gurgel MF do, Mercury JMR, Longo E, et al. Synthesis and morphological transformation of $\mathrm{BaWO}_{4}$ crystals: Experimental and theoretical insights. Ceramics International 2016;42:10913-21. doi:10.1016/ j.ceramint.2016.03.225

[138] Ribeiro RAP, Andrés J, Longo E, Lazaro SR. Magnetism and multiferroic properties at $\mathrm{MnTiO}_{3}$ surfaces: A DFT study. Applied Surface Science 2018;452:463-72. doi:10.1016/j.apsusc.2018.05.067 [139] Marks LD, Peng L. Nanoparticle shape, thermodynamics and kinetics. Journal of Physics: Condensed Matter 2016;28:053001. doi:10.1088/0953-8984/28/5/053001

[140] Jiang F, Yang L, Zhou D, He G, Zhou J, Wang F, et al. First-principles atomistic Wulff constructions for an equilibrium rutile $\mathrm{TiO}_{2}$ shape modeling. Applied Surface Science 2018;436:989-94. doi:10.1016/j.apsusc.2017.12.050

[141] Barmparis GD, Lodziana Z, Lopez N, Remediakis IN. Nanoparticle shapes by using Wulff constructions and first-principles calculations. Beilstein Journal of Nanotechnology 2015;6:361-8. doi:10.3762/bjnano.6.35

[142] Lai F, Chen Y, Guo H. Inverse Wulff construction for surface energies of coexisting and missing surfaces of crystal particles. Journal of Crystal Growth 2019;508:1-7. doi:10.1016/j.jcrysgro.2018.12.006

[143] Oliveira MC, Gracia L, Nogueira IC, Gurgel MFC, Mercury JMR, Longo E, et al. On the morphology of $\mathrm{BaMoO}_{4}$ crystals: A theoretical and experimental approach. Crystal Research and Technology 2016;51:634-44. doi:10.1002/crat.201600227

[144] Oliveira FKF, Oliveira MC, Gracia L, Tranquilin RL, Paskocimas CA, Motta FV, et al. Experimental and theoretical study to explain the morphology of CaMoO 4 crystals. Journal of Physics and Chemistry of Solids 2018;114:141-52. doi:10.1016/ j.jpcs.2017.11.019

[145] Boatti E, Vasios N, Bertoldi K. Metamaterials: Origami Metamaterials for Tunable Thermal Expansion (Adv. Mater. 26/2017). Advanced Materials 2017;29. doi:10.1002/adma.201770184

[146] Chen BG, Liu B, Evans AA, Paulose J, Cohen I, Vitelli V, et al. Topological Mechanics of Origami and Kirigami. Physical Review Letters 2016;116. doi:10.1103/physrevlett.116.135501

[147] Dudte LH, Vouga E, Tachi T, Mahadevan L. Programming curvature using origami tessellations. Nature Materials 2016;15:583-8. doi:10.1038/nmat4540

[148] Silverberg JL, Evans AA, McLeod L, Hayward RC, Hull T, Santangelo CD, et al. Using origami design principles to fold reprogrammable mechanical metamaterials. Science 2014;345:64750. doi:10.1126/science.1252876

[149] Song Z, Ma T, Tang R, Cheng Q, Wang X, Krishnaraju D, et al. Origami lithium-ion batteries. Nature Communications 2014;5. doi:10.1038/ncomms4140

[150] Wang W, Li C, Rodrigue H, Yuan F, Han M-W, Cho M, et al. Kirigami/Origami-Based Soft Deployable Reflector for Optical Beam Steering. Advanced Functional Materials 2017;27:1604214. doi:10.1002/adfm.201604214

[151] Wei ZY, Guo ZV, Dudte L, Liang HY, Mahadevan L. Geometric Mechanics of Periodic Pleated Origami. Physical Review Letters 2013;110. doi:10.1103/physrevlett.110.215501

[152] Zhao Z, Kuang X, Wu J, Zhang Q, Paulino GH, Qi HJ, et al. $3 \mathrm{D}$ printing of complex origami assemblages for reconfigurable structures. Soft Matter 2018;14:8051-9. doi:10.1039/C8SM01341A [153] Rothemund PWK. Folding DNA to create nanoscale shapes and patterns. Nature 2006;440:297-302. doi:10.1038/nature04586 [154] Liu W, Zhong H, Wang R, Seeman NC. Crystalline Two-Dimensional DNA-Origami Arrays. Angewandte Chemie International Edition 2010;50:264-7. doi:10.1002/anie.201005911

[155] Zenk J, Tuntivate C, Schulman R. Kinetics and Thermodynamics of Watson-Crick Base Pairing Driven DNA Origami Dimerization. Journal of the American Chemical Society 2016;138:3346-54. doi:10.1021/jacs.5b10502

[156] Woo S, Rothemund PWK. Self-assembly of two-dimensional DNA origami lattices using cation-controlled surface diffusion. Nature Communications 2014;5. doi:10.1038/ncomms5889

[157] Suzuki Y, Endo M, Sugiyama H. Lipid-bilayer-assisted two-dimensional self-assembly of DNA origami nanostructures. Nature Communications 2015;6. doi:10.1038/ncomms9052

[158] Wang P, Gaitanaros S, Lee S, Bathe M, Shih WM, Ke Y. Programming Self-Assembly of DNA Origami Honeycomb Two-Dimensional Lattices and Plasmonic Metamaterials. Journal of the American Chemical Society 2016;138:7733-40. doi:10.1021/ jacs.6b03966

[159] Tikhomirov G, Petersen P, Qian L. Triangular DNA Origami Tilings. Journal of the American Chemical Society 2018;140:17361-4. doi:10.1021/jacs.8b10609

[160] Ng CHB, Fan WY. Crystal Origami: Preparation of $\beta$-Ag${ }_{2} \mathrm{MoO}_{4}$ Concave and Convex Crystals with High-Index Facets. ChemNanoMat 2017;3:178-82. doi:10.1002/cnma.201600362

[161] Zhang J, Li H, Kuang Q, Xie Z. Toward Rationally Designing Surface Structures of Micro- and Nanocrystallites: Role of Supersaturation. Accounts of Chemical Research 2018;51:2880-7. doi:10.1021/acs.accounts.8b00344

[162] Yan Y, Wu Y, Yan Y, Guan W, Shi W. Inorganic-Salt-Assisted Morphological Evolution and Visible-Light-Driven Photocatalytic Performance of $\mathrm{Bi}_{2} \mathrm{WO} 6$ Nanostructures. The Journal of Physical Chemistry C 2013;117:20017-28. doi:10.1021/jp406574y

[163] Pereira W da S, Ferrer MM, Botelho G, Gracia L, Nogueira IC, Pinatti IM, et al. Effects of chemical substitution on the structural and optical properties of $\alpha-\mathrm{Ag}_{2}-2 \mathrm{xNixWO}_{4}(0 \leq \mathrm{x} \leq 0.08)$ solid solutions. Physical Chemistry Chemical Physics 2016;18:2196675. doi:10.1039/C6CP00575F

[164] Mal P, Bera G, Rambabu P, Turpu GR, Chakraborty B, Ramaniah LM, et al. Electronic, magnetic and spectroscopic properties of doped $\mathrm{Mn}(1-\mathrm{x}) \mathrm{AxWO}_{4}(\mathrm{~A}=\mathrm{Co}, \mathrm{Cu}, \mathrm{Ni}$ and $\mathrm{Fe})$ multiferroic: an experimental and DFT study. Journal of Physics: Condensed Matter 2016;29:075901. doi:10.1088/1361-648x/aa4e64

[165] López XA, Fuentes AF, Zaragoza MM, Díaz Guillén JA, Gutiérrez JS, Ortiz AL, et al. Synthesis, characterization and photocatalytic evaluation of $\mathrm{MWO}_{4}(\mathrm{M}=\mathrm{Ni}, \mathrm{Co}, \mathrm{Cu}$ and $\mathrm{Mn})$ tungstates. International Journal of Hydrogen Energy 2016;41:233127. doi:10.1016/j.ijhydene.2016.10.117

[166] Dey S, Ricciardo RA, Cuthbert HL, Woodward PM. Metal-to-Metal Charge Transfer in $\mathrm{AWO}_{4}(\mathrm{~A}=\mathrm{Mg}, \mathrm{Mn}, \mathrm{Co}, \mathrm{Ni}, \mathrm{Cu}$, or $\mathrm{Zn})$ Compounds with the Wolframite Structure. Inorganic Chemistry 2014;53:4394-9. doi:10.1021/ic4031798

[167] Ke J, Adnan Younis M, Kong Y, Zhou H, Liu J, Lei L, et al. Nanostructured Ternary Metal Tungstate-Based Photocatalysts for Environmental Purification and Solar Water Splitting: A Review. Nano-Micro Letters 2018;10. doi:10.1007/s40820-018-0222-4

[168] Fu H, Lin J, Zhang L, Zhu Y. Photocatalytic activities of a novel $\mathrm{ZnWO}_{4}$ catalyst prepared by a hydrothermal process. Applied Catalysis A: General 2006;306:58-67. doi:10.1016/j.apcata.2006.03.040 
[169] Shim H-W, Cho I-S, Hong KS, Lim A-H, Kim D-W. Wolframite-type $\mathrm{ZnWO}_{4}$ Nanorods as New Anodes for Li-Ion Batteries. The Journal of Physical Chemistry C 2011;115:16228-33. doi:10.1021/ jp204656v

[170] Zhang C, Zhang H, Zhang K, Li X, Leng Q, Hu C. Photocatalytic Activity of $\mathrm{ZnWO}_{4}$ : Band Structure, Morphology and Surface Modification. ACS Applied Materials \& Interfaces 2014;6:1442332. doi:10.1021/am503696b

[171] Lorchirachoonkul P, Nakata M, Okamoto T. Fabrication of alkali metal sulfate-doped zinc tungstate and their photoluminescence. Journal of Luminescence 2019;207:333-8. doi:10.1016/ j.jlumin.2018.11.025

[172] Dutta DP, Raval P. Effect of transition metal ion $\left(\mathrm{Cr}^{3+}\right.$ , $\mathrm{Mn}^{2+}$ and $\mathrm{Cu}^{2+}$ ) doping on the photocatalytic properties of ZnWO 4 nanoparticles. Journal of Photochemistry and Photobiology A: Chemistry 2018;357:193-200. doi:10.1016/j.jphotochem.2018.02.026

[173] Wang Y, Liping L, Li G. Solvothermal synthesis, characterization and photocatalytic performance of $\mathrm{Zn}$-rich $\mathrm{ZnWO}_{4}$ nanocrystals. Applied Surface Science 2017;393:159-67. doi:10.1016/ j.apsusc.2016.10.001

[174] Gao L, Li D, Gao F, Liu Z, Hou Y, Chen S, et al. Hydroxyl radical-aided thermal pretreatment of algal biomass for enhanced biodegradability. Biotechnology for Biofuels 2015;8. doi:10.1186/ s13068-015-0372-2

[175] Gao F, Gao L, Zhang D, Ye N, Chen S, Li D. Enhanced hydrolysis of Macrocystis pyrifera by integrated hydroxyl radicals and hot water pretreatment. Bioresource Technology 2015;179:490-6. doi:10.1016/j.biortech.2014.12.040

[176] Li Y, Zhou F, Zhu Z, Wu F. Inactivating marine microorganisms for photoelectrocatalysis by $\mathrm{ZnWO}_{4}$ electrode obtained by surfactant-assisted synthesis. Applied Surface Science 2019;467468:819-24. doi:10.1016/j.apsusc.2018.10.186

[177] Huang Y, Gao Y, Zhang Q, Cao J, Huang R, Ho W, et al. Hierarchical porous $\mathrm{ZnWO}_{4}$ microspheres synthesized by ultrasonic spray pyrolysis: Characterization, mechanistic and photocatalytic NO x removal studies. Applied Catalysis A: General 2016;515:1708. doi:10.1016/j.apcata.2016.02.007

[178] He G, Fan H, Ma L, Wang K, Ding D, Liu C, et al. Synthesis, characterization and optical properties of nanostructured $\mathrm{ZnWO}_{4}$. Materials Science in Semiconductor Processing 2016;41:404-10. doi:10.1016/j.mssp.2015.09.025

[179] Zhao X, Zhu Y. Synergetic Degradation of Rhodamine B at a Porous $\mathrm{ZnWO}_{4}$ Film Electrode by Combined Electro-Oxidation and Photocatalysis. Environmental Science \& Technology 2006;40:3367-72. doi:10.1021/es052029e

[180] Kumar GB, Sivaiah K, Buddhudu S. Synthesis and characterization of $\mathrm{ZnWO}_{4}$ ceramic powder. Ceramics International 2010;36:199-202. doi:10.1016/j.ceramint.2009.07.005

[181] Fu H, Lin J, Zhang L, Zhu Y. Photocatalytic activities of a novel $\mathrm{ZnWO}_{4}$ catalyst prepared by a hydrothermal process. Applied Catalysis A: General 2006;306:58-67. doi:10.1016/j.apcata.2006.03.040

[182] Keereeta Y, Thongtem S, Thongtem T. Enhanced photocatalytic degradation of methylene blue by $\mathrm{WO}_{3} / \mathrm{ZnWO}_{4}$ composites synthesized by a combination of microwave-solvothermal method and incipient wetness procedure. Powder Technology 2015;284:85-94. doi:10.1016/j.powtec.2015.06.046

[183] Garadkar KM, Ghule LA, Sapnar KB, Dhole SD. A facile synthesis of $\mathrm{ZnWO}_{4}$ nanoparticles by microwave assisted technique and its application in photocatalysis. Materials Research Bulletin 2013;48:1105-9. doi:10.1016/j.materresbull.2012.12.002
[184] GAO Z, SUN W, HU Y, LIU X. Anisotropic surface broken bond properties and wettability of calcite and fluorite crystals. Transactions of Nonferrous Metals Society of China 2012;22:12038. doi:10.1016/S1003-6326(11)61306-X

[185] Gao Z, Li C, Sun W, Hu Y. Anisotropic surface properties of calcite: A consideration of surface broken bonds. Colloids and Surfaces A: Physicochemical and Engineering Aspects 2017;520:53-61. doi:10.1016/j.colsurfa.2017.01.061

[186] Xu L, Tian J, Wu H, Fang S, Lu Z, Ma C, et al. Anisotropic surface chemistry properties and adsorption behavior of silicate mineral crystals. Advances in Colloid and Interface Science 2018;256:340-51. doi:10.1016/j.cis.2018.02.004

[187] GAO Z, SUN W, HU Y. Mineral cleavage nature and surface energy: Anisotropic surface broken bonds consideration. Transactions of Nonferrous Metals Society of China 2014;24:2930-7. doi:10.1016/S1003-6326(14)63428-2

[188] Gao Z, Fan R, Ralston J, Sun W, Hu Y. Surface broken bonds: An efficient way to assess the surface behaviour of fluorite. Minerals Engineering 2019;130:15-23. doi:10.1016/j.mineng.2018.09.024 [189] Kröger FA, Vink HJ. Relations between the Concentrations of Imperfections in Crystalline Solids. Solid State Physics 1956:307-435. doi:10.1016/s0081-1947(08)60135-6

[190] Scanlon MD, Peljo P, Méndez MA, Smirnov E, Girault HH. Charging and discharging at the nanoscale: Fermi level equilibration of metallic nanoparticles. Chemical Science 2015;6:2705-20. doi:10.1039/C5SC00461F

[191] Zhang N, Chen C, Mei Z, Liu X, Qu X, Li Y, et al. Monoclinic Tungsten Oxide with $\{100\}$ Facet Orientation and Tuned Electronic Band Structure for Enhanced Photocatalytic Oxidations. ACS Applied Materials \& Interfaces 2016;8:10367-74. doi:10.1021/ acsami.6b02275

[192] Huang C-K, Wu T, Huang C-W, Lai C-Y, Wu M-Y, Lin Y-W. Enhanced photocatalytic performance of $\mathrm{BiVO}_{4}$ in aqueous $\mathrm{AgNO}_{3}$ solution under visible light irradiation. Applied Surface Science 2017;399:10-9. doi:10.1016/j.apsusc.2016.12.038

[193] Wu S-Z, Li K, Zhang W-D. On the heterostructured photocatalysts $\mathrm{Ag} 3 \mathrm{VO}_{4} / \mathrm{g}-\mathrm{C} 3 \mathrm{~N} 4$ with enhanced visible light photocatalytic activity. Applied Surface Science 2015;324:324-31. doi:10.1016/ j.apsusc.2014.10.161

[194] Xu L, Wei Y, Guo W, Guo Y, Guo Y. One-pot solvothermal preparation and enhanced photocatalytic activity of metallic silver and graphene co-doped $\mathrm{BiVO}_{4}$ ternary systems. Applied Surface Science 2015;332:682-93. doi:10.1016/j.apsusc.2015.01.235

[195] Brunet L, Lyon DY, Hotze EM, Alvarez PJJ, Wiesner MR. Comparative Photoactivity and Antibacterial Properties of C60Fullerenes and Titanium Dioxide Nanoparticles. Environmental Science \& Technology 2009;43:4355-60. doi:10.1021/es803093t [196] Hoang K. Polaron formation, native defects, and electronic conduction in metal tungstates. Physical Review Materials 2017;1. doi:10.1103/physrevmaterials.1.024603

[197] Goubard-Bretesché N, Crosnier O, Payen C, Favier F, Brousse T. Nanocrystalline $\mathrm{FeWO}_{4}$ as a pseudocapacitive electrode material for high volumetric energy density supercapacitors operated in an aqueous electrolyte. Electrochemistry Communications 2015;57:61-4. doi:10.1016/j.elecom.2015.05.007

[198] Lin H-F, Liao S-C, Hung S-W. The dc thermal plasma synthesis of $\mathrm{ZnO}$ nanoparticles for visible-light photocatalyst. Journal of Photochemistry and Photobiology A: Chemistry 2005;174:82-7. doi:10.1016/j.jphotochem.2005.02.015

[199] Du J, Gebicki JM. Proteins are major initial cell targets of hydroxyl free radicals. The International Journal of Biochemistry \& Cell Biology 2004;36:2334-43. doi:10.1016/j.biocel.2004.05.012 
[200] Wang S, Gao R, Zhou F, Selke M. Nanomaterials and singlet oxygen photosensitizers: potential applications in photodynamic therapy. Journal of Materials Chemistry 2004;14:487. doi:10.1039/ b311429e

[201] Bakalova R, Ohba H, Zhelev Z, Ishikawa M, Baba Y. Quantum dots as photosensitizers? Nature Biotechnology 2004;22:13601. doi:10.1038/nbt1104-1360

[202] Fridovich I. Biological effects of the superoxide radical. Archives of Biochemistry and Biophysics 1986;247:1-11. doi:10.1016/0003-9861(86)90526-6

[203] Herrmann J-M. Heterogeneous photocatalysis: state of the art and present applications In honor of Pr. R.L. Burwell Jr. (1912-2003), Former Head of Ipatieff Laboratories, Northwestern University, Evanston (Ill). Topics in Catalysis 2005;34:49-65. doi:10.1007/s11244-005-3788-2

[204] Hoffmann MR, Martin ST, Choi W, Bahnemann DW. Environmental Applications of Semiconductor Photocatalysis. Chemical Reviews 1995;95:69-96. doi:10.1021/cr00033a004

[205] Linsebigler AL, Lu G, Yates JT. Photocatalysis on $\mathrm{TiO}_{2}$ Surfaces: Principles, Mechanisms, and Selected Results. Chemical Reviews 1995;95:735-58. doi:10.1021/cr00035a013

[206] Botelho G, Sczancoski JC, Andres J, Gracia L, Longo E. Experimental and Theoretical Study on the Structure, Optical Properties, and Growth of Metallic Silver Nanostructures in Ag${ }_{3} \mathrm{PO}_{4}$. The Journal of Physical Chemistry C 2015;119:6293-306. doi:10.1021/jp512111v

\section{Open Access}

This article is licensed under a Creative Commons Attribution 4.0 International License.

(c) The Author(s) 2018 